\title{
Anti-Biofilm and Antivirulence Activities of Metabolites from Plectosphaerella cucumerina against Pseudomonas aeruginosa
}

\author{
Jinwei Zhou ${ }^{1+}$, Shiyuan $\mathrm{Bi}^{1+}$, Hongjuan Chen ${ }^{2}$, Tongtong Chen ${ }^{1}$, Rui Yang ${ }^{1}$, Minghui $\mathrm{Li}^{1}$, \\ Yonghong $\mathrm{Fu}^{1}$ and $\mathrm{Ai}$-Qun Jia ${ }^{1,3 *}$ \\ ${ }^{1}$ School of Environmental and Biological Engineering, Nanjing University of Science and Technology, Nanjing, China, ${ }^{2}$ State \\ Key Laboratory of Pharmaceutical Biotechnology, Nanjing University, Nanjing, China, ${ }^{3}$ State Key Laboratory of Marine \\ Resource Utilization in South China Sea, Key Laboratory of Tropical Biological Resources of Ministry Education, Hainan \\ University, Haikou, China
}

This study reported the efficacy of the metabolites of Plectosphaerella cucumerina, one phyllosphere fungus from Orychophragmus violaceus, against $P$ seudomonas aeruginosa quorum sensing (QS) and QS-regulated biofilms. The minimum inhibitory concentration
OPEN ACCESS

Edited by:

Yuji Morita,

Aichi Gakuin University, Japan

Reviewed by:

Mona I. Shaaban,

Mansoura University, Egypt

Francesco Imperi,

Sapienza University of Rome, Italy

*Correspondence:

Ai-Qun Jia

aiqunj302@njust.edu.cn

${ }^{\dagger}$ These authors have contributed equally to this work.

Specialty section:

This article was submitted to Antimicrobials, Resistance and

Chemotherapy,

a section of the journal

Frontiers in Microbiology

Received: 06 February 2017 Accepted: 13 April 2017 Published: 03 May 2017

Citation:

Zhou J, Bi S, Chen H, Chen T, Yang $R$,

Li M, Fu Y and Jia A-Q (2017)

Anti-Biofilm and Antivirulence Activities of Metabolites from Plectosphaerella cucumerina against Pseudomonas aeruginosa. Front. Microbiol. 8:769. doi: 10.3389/fmicb.2017.00769 (MIC) of the ethyl acetate (EtOAc) extract from $P$. cucumerina against $P$. aeruginosa PAO1 was $1.25 \mathrm{mg} \mathrm{mL}^{-1}$. At sub-MIC concentrations, $P$. cucumerina extract $(0.25-1 \mathrm{mg}$ $\mathrm{mL}^{-1}$ ) not only inhibited biofilm formation but also disrupted preformed biofilms of $P$. aeruginosa PAO1 without affecting its growth. Fluorescence and scanning electron microscope (SEM) showed architectural disruption of the biofilms when treated with $P$. cucumerina metabolites. Further investigation demonstrated that metabolites in P. cucumerina attenuated the QS-dependent virulence factors. LC-MS/MS spectra coupled with experimentally standard samples suggested that patulin and emodin might act as the principal components possessing anti-biofilm and antivirulence activities. This is the first report of (1) the isolation of $P$. cucumerina from the phyllosphere of $O$. violaceus and (2) anti-biofilm, antivirulence, and biofilm disruption activities of this fungus. Thus, this study provides fascinating new pathways for screening antipathogenic agents.

Keywords: Plectosphaerella cucumerina, phyllosphere fungus, Pseudomonas aeruginosa, biofilm, quorum sensing

\section{INTRODUCTION}

Most pathogenic bacteria can form biofilms under diverse conditions (Hall-Stoodley and Stoodley, 2005). Among biofilm forming microbial pathogens, Pseudomonas aeruginosa is the most notorious bacterium causing chronic diseases in nature (Morita et al., 2014). The pathogenicity of $P$. aeruginosa is mainly owing to the biofilms, which make this organism more resistant to physical and chemical treatment (Imperi et al., 2014; Pompilio et al., 2015). Biofilm formation is a highly regulated process that is closely associated with quorum sensing (QS) (Qin et al., 2014). QS is a bacterial communication phenomenon that relies on secreted signals for coordinating group behaviors (Kim et al., 2015). N-acylated L-homoserine lactones (AHLs) are released as autoinducers to facilitate QS of Gram-negative bacteria (LaSarre and Federle, 2013). In many cases, QS signals were directly employed by bacteria to control biofilm formation and production of virulence 
factors, such as pyocyanin and rhamnolipids (Rutherford and Bassler, 2012). Pyocyanin induces oxidative stress and positively correlates with disease severity (Hunter et al., 2012). Rhamnolipids play vital roles in chronic infection by facilitating biofilm maturation and immune evasion (Zulianello et al., 2006).

P. aeruginosa owns three QS systems, las, rhl, and pqs (Kim et al., 2015). Each system possesses one transcriptional regulator and its related signals. The signals $\mathrm{N}$-(3-oxododecanoyl)-Lhomoserine lactone (3-oxo-C12-HSL, OdDHL) and N-butanoylL-homoserine lactone (C4-HSL, BHL) are produced by the las and $r h l$ systems, and the autoinducer 2-heptyl-3-hydroxy-4(1H)quinolone, known as Pseudomonas quinolone signal (PQS) from the pqs system (Chan et al., 2015; Liu et al., 2015). There is a regulatory hierarchy between these three systems, with the $r h l$ and pqs systems regulated by the las system (Smith, 2003). The signals can bind their cognate transcriptional regulators, respectively. The transcriptional regulators will be activated once these signals reach a threshold (Venturi, 2006). The QS signals of $P$. aeruginosa have been detected in the lungs of infected cystic fibrosis patients (Singh et al., 2000; Favre-Bonté et al., 2002). Furthermore, a striking altered structure of biofilms and reduced virulence were observed in $P$. aeruginosa mutants that showed QS deficit (Davies et al., 1998; Pearson et al., 2000). A lasI mutant formed flat, abnormal and undifferentiated biofilms which were significantly different from the wild-type biofilms (Davies et al., 1998). Thus, the QS is being regarded as an attractive target for developing new therapeutics.

There are basically two strategies for interfering with the Gram-negative QS systems, known as enzyme degradation and the small molecules binding (Uroz et al., 2009). The latter has been extensively investigated by employing AHL analogs to bind the QS receptor site (Galloway et al., 2011). Due to the regulatory hierarchy of $P$. aeruginosa QS systems, the vast studies have focused on LasR (Welsh et al., 2015). For example, Geske (Geske et al., 2008) has synthesized a series of small molecules capable of sequestering OdDHL, effectively quenching the Las circuit. Compounds that specifically target Rhl are scarce. The synthetic AHL analogs mCTL and mBTL have been reported to act as RhlR antagonists that strongly inhibit pyocyanin production (O'Loughlin et al., 2013). Recently, more efforts have been aimed at screening antagonists of the pqs system (Storz et al., 2012; Lu et al., 2013). Though these synthetic AHLs show potential as anti-QS agents, production costs and success rates make drugs from natural products preferable (Kong et al., 2009). Fungi are renowned sources of natural products with an array of biological activities, such as antioxidant, antiviral, cytotoxic, and antibacterial (Kandasamy et al., 2015; Zhang S. P. et al., 2016). Fungi coexist with bacteria but lack active immune systems (Rasmussen et al., 2005). They instead rely on chemical defense mechanisms (Rasmussen et al., 2005). Recently, a series of anti-QS compounds such as penicillic acid (Wang et al., 2011), w-hydroxyemodin, emodic acid, and (+)-2'S-isorhodoptilometrin (Figueroa et al., 2014) have been isolated from Penicillium sp. Thus, the use of fungi to control pathogenic bacteria is believed to be a renewable approach. Phyllosphere should deserve a special attention because it is a vital habitat for QS quenching fungi (Lindow and Brandl, 2003). Notably, fungi have the capacity to reside within the same ecological niche as their pathogenic counterparts. This could protect their host plants effectively (Osono, 2006). In China, Orychophragmus violaceus has been used as a medicinal and edible plant for centuries (Zhan et al., 2016). However, literature about the bioactive potential of $O$. violaceus is limited (Ping, 2009). Furthermore, phyllosphere fungi derived from $O$. violaceus have not been reported. In order to screen new QS inhibitors, the aim of this work was to explore phyllosphere fungi that could produce antivirulence compounds and study the influence of their metabolites on the QS mediated biofilms of $P$. aeruginosa PAO1. Finally, the principal antivirulence compounds contained in the metabolites of Plectosphaerella cucumerina were also investigated.

\section{MATERIALS AND METHODS Isolation and Identification of the Phyllosphere Fungi}

Healthy leaves were randomly collected from $O$. violaceus at different locations grown in Nanjing University of Science and Technology, Nanjing, China. To isolate the phyllosphere fungi, mixed leaves $(10 \mathrm{~g})$ were placed in sterile flasks containing $30 \mathrm{~mL}$ of potassium phosphate buffer (PBS, $0.1 \mathrm{M}, \mathrm{pH} 7.0$ ), and sonicated for $10 \mathrm{~min}$ at $40 \mathrm{KHz}$ power level at $20^{\circ} \mathrm{C}$ using a ultrasonic cleaner (Lv et al., 2013). The mixture was then vortexed for $10 \mathrm{~min}$ and the resulting suspension was serially diluted and spread onto Czapek-dox agar plates $\left(0.3 \% \mathrm{NaNO}_{3}, 0.1 \%\right.$ $\mathrm{K}_{2} \mathrm{HPO}_{4}, 0.05 \% \mathrm{MgSO}_{4} \cdot 7 \mathrm{H}_{2} \mathrm{O}, 0.05 \% \mathrm{KCl}, 0.001 \% \mathrm{FeSO}_{4}, 3 \%$ sucrose, and 1.5\% agar; Han et al., 2016) supplemented with streptomycin sulfate $\left(250 \mathrm{mg} \mathrm{L}^{-1}\right)$ and ampicillin $\left(250 \mathrm{mg} \mathrm{L}^{-1}\right)$ to inhibit bacterial growth. The plates were incubated at $24^{\circ} \mathrm{C}$ and the purified isolates were stored at $-80^{\circ} \mathrm{C}$ for further use. Colony morphology was determined after 14 days of incubation on Potato Dextrose Agar (20\% potato, 2\% dextrose, 2\% agar, PDA; Bai and Shaner, 1996) at $24^{\circ} \mathrm{C}$ in darkness. Fungal internal transcribed spacer (ITS) region (ITS1, 5.8S rRNA and ITS4) (Figueroa et al., 2014; Zhang T. et al., 2016), was amplified using primers ITS-1 (5'-TCCGTAGGTGAACCTGCGG-3') and ITS4 (5'-TCCTCCGCTTATTGATATGC-3'; Zhang T. et al., 2016). PCR were assayed in $25 \mu \mathrm{L}$ of mixtures with $2.5 \mu \mathrm{L}$ of $10 \times$ buffer (with $\mathrm{Mg}^{2+}$ ) (Sangon Biotech, China), $1 \mu \mathrm{L}$ of dNTP (2.5 mM) (Sangon Biotech, China), $0.2 \mu \mathrm{L}$ of enzymes (Sangon Biotech, China), $1 \mu \mathrm{L}$ of primers and $0.5 \mu \mathrm{L}$ of DNA. The applied temperature cycle was: initial denaturation at $95^{\circ} \mathrm{C}$ for $5 \mathrm{~min}$, 30 cycles of $45 \mathrm{~s}$ of denaturation at $95^{\circ} \mathrm{C}, 45 \mathrm{~s}$ of annealing at $55^{\circ} \mathrm{C}, 1 \mathrm{~min}$ of extension at $72^{\circ} \mathrm{C}$, and a final extension for $10 \mathrm{~min}$ at $72^{\circ} \mathrm{C}$. PCR products were purified employing a SanPrep extraction kit (Sangon Biotech, China). The sequencing reaction was assayed through the Applied Biosystems 3730XL automated sequencer system. The sequences were compared with Genbank databases followed by sequence alignment. Phylogenetic trees were performed by neighbor-joining algorithm, using MEGA version 4.1 (Tempe, AZ, USA).

\section{Indicator Strains and Growth Conditions}

The bacterial strains such as Agrobacterium tumefaciens KYC55 (pJZ372, pJZ 384, pJZ410) and $P$. aeruginosa PAO1 (wild type) were used in this study based on their QS dependent 
phenotypes. P. aeruginosa PAO1 was kindly provided by Prof. Qianhong Gong, Ocean University of China (Qingdao, China). A. tumefaciens KYC55 was kindly presented by Prof. Jun Zhu, University of Pennsylvania (Philadelphia, USA). A. tumefaciens KYC55 was propagated in Luria Bertani medium (LB, Sangon Biotech, China) containing $1 \%$ tryptone, $0.5 \%$ yeast extract, and $1 \% \mathrm{NaCl}$ (Wu et al., 2015) without antibiotics at $30^{\circ} \mathrm{C} . P$. aeruginosa $\mathrm{PAO} 1$ was cultivated in $\mathrm{LB}$ at $37^{\circ} \mathrm{C}$ unless otherwise specified.

\section{Preparation of Extract of $\boldsymbol{P}$ cucumerina}

$P$. cucumerina was cultivated in PDA medium for 7 days until the mycelium was widespread over the plate. Two hundred and fifty milliliters Erlenmeyer flasks containing $100 \mathrm{~mL}$ of Fungus No. 2 medium (2\% sorbitol, $2 \%$ maltose, $1 \%$ glutamine, $1 \%$ glucose, $0.3 \%$ yeast extract, $0.05 \%$ tryptophan, $0.05 \% \mathrm{KH}_{2} \mathrm{PO}_{4}, 0.03 \%$ $\mathrm{MgSO}_{4}, \mathrm{pH} 6.4$, autoclaved at $121^{\circ} \mathrm{C}$ for $15 \mathrm{~min}$; Xin et al., 2007) were inoculated with the fungal strain. The flasks were incubated at $28^{\circ} \mathrm{C}$ at $140 \mathrm{rpm}$ for $15 \mathrm{~d}$. After incubation, the fungal biomass and the fermentation broth were separated by centrifugation at $10,000 \mathrm{rpm}$ for $15 \mathrm{~min}$. The fungal biomass was lyophilized using a lyophilizer (LGJ-25C, Four Ring Science Instrument Plant Beijing Co., Ltd., Beijing, China) at $-50^{\circ} \mathrm{C}$ for $15 \mathrm{~h}$. The fungal biomass and the fermentation broth were extracted with the same volume of ethyl acetate (EtOAc). The solvent was pooled and eliminated under reduced pressure and residues were dissolved in methanol $(\mathrm{MeOH})$ and stored at $-20^{\circ} \mathrm{C}$.

\section{The Minimum Inhibitory Concentration and Growth Measurement}

$P$. cucumerina extract was tested against the selected bacterial strains to determine their minimum inhibitory concentration (MIC) according to Clinical and Laboratory Standards Institute (CLSI) (2015) with an inoculum of about $1-5 \times 10^{5} \mathrm{CFU} \mathrm{mL}^{-1}$. Serial two-fold dilution $\left(0.16-10 \mathrm{mg} \mathrm{mL}^{-1}\right)$ of extract was performed in Müller-Hinton broth (Sangon Biotech, China). The MIC was the lowest concentration of extract that inhibited visible cell growth. For growth measurement, overnight cultures of $P$. aeruginosa PAO1 were subcultured into $\mathrm{LB}$ medium to achieve $\mathrm{OD}_{620}$ of 0.05 . The cultures were then supplemented with extract with varying concentrations and incubated at $37^{\circ} \mathrm{C}$ at $150 \mathrm{rpm}$ for $15 \mathrm{~h}$. In this study, the extract was firstly set into a high concentration with an amount of $\mathrm{MeOH}$. The extract was then diluted into different concentrations with $\mathrm{MeOH}$. All test extracts with the varying concentrations were supplemented with the same volume. The same amount of distilled water (0) and $\mathrm{MeOH}$ served as negative controls. Growth was evaluated by measuring $\mathrm{OD}_{620}$ using a microplate reader (Biotek Elx800, USA) in triplicate.

\section{Analysis of the AHLs Produced by $P$ aeruginosa}

To assess the inhibitory effect of $P$. cucumerina extract on the levels of C4-HSL and 3-oxo-C12-HSL produced by P. aeruginosa, the overnight cultures of $P$. aeruginosa PAO1 were diluted 1:1,000 into $50 \mathrm{~mL}$ of $\mathrm{LB}$ and incubated at $37^{\circ} \mathrm{C}$ at $200 \mathrm{rpm}$ for $48 \mathrm{~h}$. The extract was added as treated group while the same amount of water and $\mathrm{MeOH}$ were used in control groups. After incubation, cells were separated from culture fluids by 15min centrifugation $\left(12,000 \mathrm{rpm}, 4^{\circ} \mathrm{C}\right)$. Cell-free culture fluids were extracted with an equal volume of acidified ethyl acetate $(0.5 \%$ formic acid) for three times. The solvent was pooled and eliminated under reduced pressure at $35^{\circ} \mathrm{C}$ and residues were dissolved in $\mathrm{MeOH}$ and stored at $-20^{\circ} \mathrm{C}$ prior to analysis. The levels of AHLs were determined using LC-MS/MS as described previously (Morin et al., 2003). AHLs were analyzed using HPLC system (SHIMADZU) equipped with a Inertisl-C18 column (250 $\times 4.6 \mathrm{~mm}, 5 \mu \mathrm{m}$; Shimadzu, Tokyo, Japan). Mobile phase A was formic acid $(0.1 \%)$ and ammonium formate $(5.0 \mathrm{mM})$ in water. Mobile phase $\mathrm{B}$ was $\mathrm{MeOH}$. The flow rate was set as 0.4 $\mathrm{mL} \min ^{-1}$. The injection volume was $10.0 \mu \mathrm{L}$. The gradient was set as: $1-5 \mathrm{~min}, 20-50 \% \mathrm{~B} ; 5-20 \mathrm{~min}, 50-90 \% \mathrm{~B}$. The eluates were determined by a ThermoFinnigan LCQ Classic system (San Jose, CA) using the positive mode. The nebulizer was set as 15 psi. The drying gas was set as $7 \mathrm{~mL} \mathrm{~min}^{-1}$ and the temperature was maintained at $300^{\circ} \mathrm{C}$. Full-scan MS was from $\mathrm{m} / z 100$ to 1,000 . The peaks corresponding to C4-HSL and 3-oxo-C12-HSL were identified according to their fragment MS ions and the retention time of commercial standards (Sigma-Aldrich, USA) for each AHL. The area of the ion $m / z 102$ was selected to quantify each AHL due to its specificity and better signal-to-noise ratio. The extracted ion chromatograms were employed for area calculation. This is a relative quantification approach for AHLs without the need of standard curve. Data were normalized to the level of the water control for relative quantification.

\section{Anti-Biofilm Formation Assay}

$P$. aeruginosa $\mathrm{PAO} 1$ biofilms were quantified based on the tube method (Panda et al., 2016). Overnight, P. aeruginosa cultures were diluted 1:50 into $200 \mu \mathrm{L}$ of Trypticase Soytone broth (TSB, $1.7 \%$ tryptone, $0.3 \%$ soy protone, $0.25 \%$ glucose, $0.5 \% \mathrm{NaCl}$, $0.25 \% \mathrm{KH}_{2} \mathrm{PO}_{4}, \mathrm{pH} 7.2, \mathrm{OD}_{620} \approx 0.1$; Cycoń et al., 2016) with varying concentrations of extract. Distilled water and $\mathrm{MeOH}$ served as negative controls. The tubes were incubated at $37^{\circ} \mathrm{C}$ for $24 \mathrm{~h}$ without agitation. After incubation, excess broth and the planktonic cells were removed. For quantification of the total biofilm biomass, the tubes were washed with PBS ( $\mathrm{pH} 7.2)$ and then dried at $60^{\circ} \mathrm{C}$ for $30 \mathrm{~min}$. The biofilms were stained with $200 \mu \mathrm{L}$ of $0.1 \%$ crystal violet for $15 \mathrm{~min}$ and then rinsed off by distilled water and bounded crystal violet was re-solubilized in $100 \%$ ethanol. The OD was determined at $570 \mathrm{~nm}$ using a microplate reader (Biotek Elx800, USA). The biofilm biomass was normalized to the level of the water control for relative quantification.

Subsequently, the effect of extract on exopolysaccharide (EPS) was determined using the sonication method (Liu et al., 2007; Gong et al., 2009; Kim and Park, 2013). Briefly, $P$. aeruginosa $\mathrm{PAO} 1$ was incubated in $\mathrm{AB}$ medium $(300 \mathrm{mM} \mathrm{NaCl}$, $50 \mathrm{mM} \mathrm{MgSO}_{4}, 10 \mathrm{mM}$ potassium phosphate, $0.2 \%$ vitamin-free casamino acids, $1 \%$ glucose, $1 \mathrm{mM}$ L-arginine; Kim and Park, $2013)$ in the absence and presence of extract $\left(0.25-1 \mathrm{mg} \mathrm{mL}^{-1}\right)$ at $37^{\circ} \mathrm{C}$ for $24 \mathrm{~h}$ without agitation. The cultures were then centrifuged at $12,000 \mathrm{rpm}$ for $15 \mathrm{~min}$ to remove the cells. The cell pellets were resuspended in $10 \mathrm{~mL}$ of $\mathrm{KCl}(0.01 \mathrm{M})$ 
and then sonicated with a sonicator (YJ96-II, Ningbo Scientz Biotechnology Co., Ltd., Ningbo, China) with four cycles of $5 \mathrm{~s}$ on and $5 \mathrm{~s}$ pauses at $3.5 \mathrm{~Hz}$ power level. The sonicated suspension was centrifuged $\left(12,000 \mathrm{rpm}, 4^{\circ} \mathrm{C}\right)$ once again for $20 \mathrm{~min}$. The supernatant was filtered through a $0.22-\mu \mathrm{m}$ filter (Millipore, Fisher Scientific). For carbohydrate quantification, $50 \mu \mathrm{L}$ of the filtrate coupled with $150 \mu \mathrm{L}$ of concentrated sulfuric acid were added into a 96-well polystyrene microtiter plate and incubation at room temperature for $30 \mathrm{~min}$. The mixture was added with $5 \%$ phenol and incubated at $90^{\circ} \mathrm{C}$ in the water bath for $5 \mathrm{~min}$. The amount of carbohydrate was quantified by measuring $\mathrm{OD}_{490}$ and the relative EPS production was calculated.

\section{Biofilm Disruption Assay}

The overnight cultures of $P$. aeruginosa PAO1 were diluted 1:50 into $200 \mu \mathrm{L}$ of TSB, and incubated statically in $1.5-\mathrm{mL}$ tube at $37^{\circ} \mathrm{C}$ for $24 \mathrm{~h}$. The biofilm was then treated with varying concentration of extract for $24 \mathrm{~h}$. After incubation, both the culture medium and the planktonic cells were removed. For quantification of the total biofilm biomass, the tubes were washed with PBS for three times and then dried at $60^{\circ} \mathrm{C}$ for $30 \mathrm{~min}$. The biofilm biomass was determined employing the crystal violet staining method as described above.

\section{Microscopy Analysis}

For the biofilm inhibition assay, the 96-well, round-bottom, sterile polystyrene microtiter plate (Coming Costar, Ltd., New York, USA) with circular glass slides (diameter of $14 \mathrm{~mm}$ ) and overnight cultures of $P$. aeruginosa $\mathrm{PAO} 1$ were supplemented with extract and incubated at $37^{\circ} \mathrm{C}$ for $24 \mathrm{~h}$ without agitation. Distilled water and $\mathrm{MeOH}$ served as negative controls. For quantification of the total biofilm biomass, the glass slides were washed with PBS for three times and then dried at $60^{\circ} \mathrm{C}$. Biofilms were stained with $0.1 \%$ crystal violet or $0.01 \%$ acridine orange for $15 \mathrm{~min}$. After which, biofilms were observed under light microscope (Nikon 80i, Japan) and fluorescence microscope (Nikon 80i, Japan), respectively.

For the biofilm disruption assay, after biofilms formed, the wells were supplemented with or without extract and incubated for $24 \mathrm{~h}$. The biofilms that adhered to the glass slides were then stained using acridine orange for $15 \mathrm{~min}$ and visualized under fluorescence microscope. For SEM analysis, slides coated with biofilms were fixed using $2.5 \%$ glutaraldehyde and dehydrated with ethanol $(50,70,80,90$, and 100\%). The slides were subsequently dried, gold coated and observed under SEM (JSM6360, JEOL, Tokyo, Japan).

\section{Effect of Extract on $P$. aeruginosa Virulence Factors}

Protease activity was determined according to $\mathrm{Wu}$ et al. (2016) using the azocaserin method. Azocaserin is a suitable substrate for the measurement of protease activity (Hazen et al., 1965). During digestion, the colored components are formed and soluble in trichloroacetic acid. After removal of the undigested substrate, the color, which is proportional to the proteolytic activity of the enzyme, can be measured by a microplate reader (Hazen et al., 1965). Briefly, $150 \mu \mathrm{L}$ of sterile supernatant of $P$. aeruginosa PAO1 and $250 \mu \mathrm{L}$ of $2 \%$ azocasein (Sangon Biotech, China) in $50 \mathrm{mM}$ Tris- $\mathrm{HCl}$ were incubated at $37^{\circ} \mathrm{C}$ for $4 \mathrm{~h}$. The undigested substrate was precipitated with trichloroacetic acid $(10 \%, 1.2 \mathrm{~mL})$ for $20 \mathrm{~min}$ and then centrifuged at $12,000 \mathrm{rpm}$ for $10 \mathrm{~min}$, after which the supernatant was supplemented with $1.4 \mathrm{~mL}$ of $1 \mathrm{M} \mathrm{NaOH}$. The absorbance was then measured at $440 \mathrm{~nm}$.

Elastase activity was measured as described previously (Ohman et al., 1980). Briefly, $900 \mu \mathrm{L}$ of Elastin congo red (ECR) buffer ( $1 \mathrm{mM} \mathrm{CaCl} 2,100 \mathrm{mM}$ Tris, pH 7.5) with $20 \mathrm{mg}$ ECR was mixed with $100 \mu \mathrm{L}$ of culture supernatant and incubated for $3 \mathrm{~h}$ at $37^{\circ} \mathrm{C}$. Absorbance of the supernatant was measured at $495 \mathrm{~nm}$ after removing the insoluable ECR by centrifugation at 12,000 rpm for $10 \mathrm{~min}$.

Quantification of pyocyanin was performed as previously described with minor modification (O'Loughlin et al., 2013). P. aeruginosa strains were propagated in a $2-\mathrm{mL}$ Pseudomonas broth containing $2 \%$ bacto peptone, $0.14 \%$ $\mathrm{MgCl}_{2}, 1 \% \mathrm{~K}_{2} \mathrm{SO}_{4}$, and $1 \%$ glycerol and were incubated at $37^{\circ} \mathrm{C}$ at $150 \mathrm{rpm}$ for $17 \mathrm{~h}$. Cells were separated from culture fluids by 15 -min centrifugation at $12,000 \mathrm{rpm}$. Cell-free culture fluids were used to quantify pyocyanin by measuring $\mathrm{OD}_{695}$.

Rhamnolipids were assayed using the orcinol method with minor modification (Kim et al., 2015). Culture supernatant with the volume of $300 \mu \mathrm{L}$ was extracted with $600 \mu \mathrm{L}$ of diethyl ether. The organic phase was collected and evaporated to dryness under reduced pressure at $35^{\circ} \mathrm{C}$ and then added with $100 \mu \mathrm{L}$ of deionized water. Orcinol solution with the volume of $900 \mu \mathrm{L}$ (0.19\%, Sigma-Aldrich) in $53 \% \mathrm{H}_{2} \mathrm{SO}_{4}$ was mixed with $100 \mu \mathrm{L}$ of each sample. The mixture was heated at $80^{\circ} \mathrm{C}$ for $30 \mathrm{~min}$, and then cooled at room temperature for $15 \mathrm{~min}$. Rhamnolipids concentration was determined at $421 \mathrm{~nm}$.

Quantification of alginate was assayed as described previously (Owlia et al., 2007). Sterile-filtered supernatant $(70 \mu \mathrm{L})$ of $P$. aeruginosa $\mathrm{PAO} 1$ was mixed with $600 \mu \mathrm{L}$ of boric acid/ $\mathrm{H}_{2} \mathrm{SO}_{4}$ $(4: 1, \mathrm{v} / \mathrm{v})$. The mixture was vortexed and supplemented with $20 \mu \mathrm{L}$ of $0.2 \%$ carbazole solution. The mixture was vortexed and incubated at $55^{\circ} \mathrm{C}$ for $30 \mathrm{~min}$. The $\mathrm{OD}$ value was determined at $530 \mathrm{~nm}$.

Swimming and swarming motilities were assayed according to Sheng et al. (2015). For swimming, $3 \mu \mathrm{L}$ of overnight cultures of $P$. aeruginosa PAO1 were inoculated in the swimming agar medium ( $1 \%$ tryptone, $0.5 \% \mathrm{NaCl}, 0.3 \%$ agar) in the presence or absence of extract. For swarming motility, $5 \mu \mathrm{L}$ of overnight cultures were inoculated in the swarming agar medium containing $1 \%$ tryptone, $0.5 \% \mathrm{NaCl}$, $0.3 \%$ agar, and $0.5 \%$ glucose. Plates were incubated at $37^{\circ} \mathrm{C}$ for $24 \mathrm{~h}$.

\section{Thermal Stability}

P. cucumerina extract $\left(1 \mathrm{mg} \mathrm{mL}^{-1}\right)$ was exposed to a rising temperature gradient for $10 \mathrm{~min}\left(30,50,70\right.$, and $\left.95^{\circ} \mathrm{C}\right)$. The 
stability of $P$. cucumerina extract was evaluated by an antipyocyanin assay as described above. Distilled water and $\mathrm{MeOH}$ served as negative controls. Quantification of pyocyanin was performed by measuring $\mathrm{OD}_{695}$.

\section{LC-MS/MS Analysis of the Extract}

The $P$. cucumerina extract was analyzed using HPLC system (SHIMADZU) equipped with a XB-C18 column $(100 \times 2.1 \mathrm{~mm}$, $3 \mu \mathrm{m}$; Welch Ultimate, Shanghai, China). The gradient was set as: $1-5 \mathrm{~min}, 5-20 \% \mathrm{~B}$; 5-8 $\mathrm{min}, 20-40 \% \mathrm{~B} ; 8-20 \mathrm{~min}, 40-100 \% \mathrm{~B}$; $20-25,100-100 \%$ B; $25-30 \mathrm{~min}, 100-5 \%$ B. Detection wavelength was $212 \mathrm{~nm}$. For MS system, the nebulizer was set as 55 psi. The drying gas was set as $15 \mathrm{~L} \mathrm{~min}^{-1}$ and the temperature was maintained at $500^{\circ} \mathrm{C}$. Full-scan MS was from $\mathrm{m} / z 100$ to 1,000 . Further verification and quantitation of patulin and emodin was performed by LC-MS/MS using their corresponding standards (Sangon Biotech, China). Electrospray ionization was conducted in the negative mode under the same conditions as mentioned above.

\section{Effect of Patulin and Emodin on $P$. aeruginosa Biofilms and Virulence Factors}

Furthermore, pure compounds of patulin $\left(25\right.$ and $\left.50 \mu \mathrm{g} \mathrm{mL}^{-1}\right)$ and emodin (25 and $50 \mu \mathrm{g} \mathrm{mL}^{-1}$ ) were added to the growth medium to analyze their activities on $P$. aeruginosa virulence factors and biofilms. In this assay, patulin was dissolved in distilled water while emodin was dissolved in $\mathrm{MeOH}$. Biofilms, pyocyanin, protease, elastase, and swimming motility were assayed as mentioned above.

\section{Statistical Analysis}

Data were expressed as mean values \pm SD. The Levene's test for homogeneity of variance was applied to assess the equality of variances for all the variables before variance analysis. Statistically difference was determined by Levene's test coupled with ANOVA followed by Tukey-Kramer test. Statistics were performed using SPSS 18.0 software (SPSS,
Inc., Chicago, IL, USA). $P \leq 0.05$ was considered as significant.

\section{RESULTS}

\section{Identification of the Phyllosphere Fungus}

A total of 41 fungi were isolated from the healthy leaves of $O$. violaceus based on their morphological characteristics. The anti-QS capacity was preliminarily screened using $A$. tumefaciens KYC55 as reporter strain. The A. tumefaciens KYC55 generates the AHL receptor TraR, which can sense exogenous AHLs. This anti-QS capacity was determined by comparing the competitive binding of the AHL molecules of A. tumefaciens and fungal extract to the AHL receptors. The competition was evaluated colormetrically. Among 41 isolated fungi, 7 kinds of fungi showed anti-QS capacities against A. tumefaciens KYC55 (Figure S1). However, only one fungus coded "B-JW-304" was selected for further study due to its potent antivirulence and antibiofilm capacities against $P$. aeruginosa PAO1. No antivirulence and anti-biofilm capacities were observed in the other 6 fungi. Colonies of this fungus on PDA were slimy, flat, appressed, with sparse aerial mycelium (Figure S2a). Aerial mycelium varied from buff to salmon pink. Mycelium branched, septate, with abundant anastomosis, forming hyphal coils (Figure S2b). Conidia hyaline, smooth, ellipsoid tapering to rounded ends (Figures S2c,d). Using molecular studies (based on ITS1-5.8SITS4), B-JW-304 was identified as P. cucumerina (Figure 1). The 18S rDNA sequence was deposited in Genbank under the accession number KX822030. P. cucumerina is a wellknown pathogen that could cause fruit rot (Carlucci et al., 2012). At present, most reports about P. cucumerina are associated with its pathogenic effect and biological control (Sanchez-Vallet et al., 2010; Gamir et al., 2012). However, literature about the secondary metabolites secreted by $P$. cucumerina is scarce. Therefore, it is valuable to investigate the metabolites and evaluate their bioactive capacities from P. cucumerina.

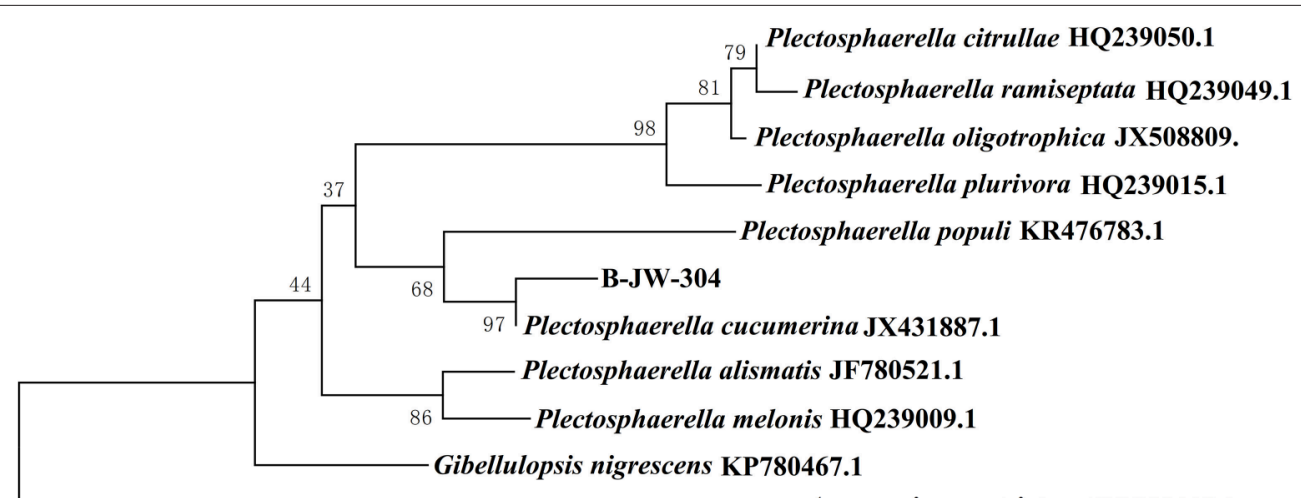

Acremonium restrictum HQ232119.1

FIGURE 1 | Evolutionary relationships between P. cucumerina B-JW-304 with another 10 related strains. 


\section{Determination of MIC of $P$. cucumerina Extract}

The yield of EtOAc extract in terms of dry weight was $314.8 \mathrm{mg}$ $\mathrm{L}^{-1}$ of the pooled extract from cells and supernatant. The MIC of extract against $P$. aeruginosa PAO1 was $1.25 \mathrm{mg} \mathrm{mL}^{-1}$. The growth profile of $P$. aeruginosa PAO1 was evaluated using $P$. cucumerina extract at sub-MIC concentrations for $15 \mathrm{~h}$ (Figure 2). Results showed that $P$. cucumerina extract treatment with the concentration of $0.25,0.5,0.75$, and $1 \mathrm{mg} \mathrm{mL}^{-1}$ had no inhibitory effect on cell growth comparing with the water control during the stationary growth phase (Table S1). However, the growth was statistically different between the cultures with $\mathrm{MeOH}$ and $1 \mathrm{mg} \mathrm{mL}^{-1}$ of extract $(P<0.05)$ at 12 and $14 \mathrm{~h}$ while not statistically different at 13 and $15 \mathrm{~h}(P>0.05$; Table S2). Therefore, we speculated that the experimental error might lead to such difference. To further validate the data, the growth assay was performed again. The bacterial viable count was performed after incubation for $24 \mathrm{~h}$. The reason for selecting $24 \mathrm{~h}$ was that most assays of this study were determined after incubation for $24 \mathrm{~h}$. The results showed that extract with the concentration of $1 \mathrm{mg} \mathrm{mL} \mathrm{m}^{-1}$ had no inhibitory effect on $P$. aeruginosa growth comparing with the two negative controls (Figure S3).

\section{Effect of $P$. cucumerina Extract on AHLs Levels}

In $P$. aeruginosa, the regulatory mechanism between las and rhl is clear. However, the molecular mechanism of pqs in coordinating virulence is currently unknown (Welsh et al., 2015). Therefore, in this study, the putative anti-QS activity of extract against $P$. aeruginosa was determined by quantitating the AHLs levels produced by this strain. LC-MS/MS analysis confirmed the presence of C4-HSL and 3-oxo-C12-HSL (Figures 3A,B). Treatment with $P$. cucumerina extract caused a decrease in both peaks and areas of C4-HSL and 3-oxo-C12-HSL as shown in the chromatograms (Figure 3B). The relative quantification of

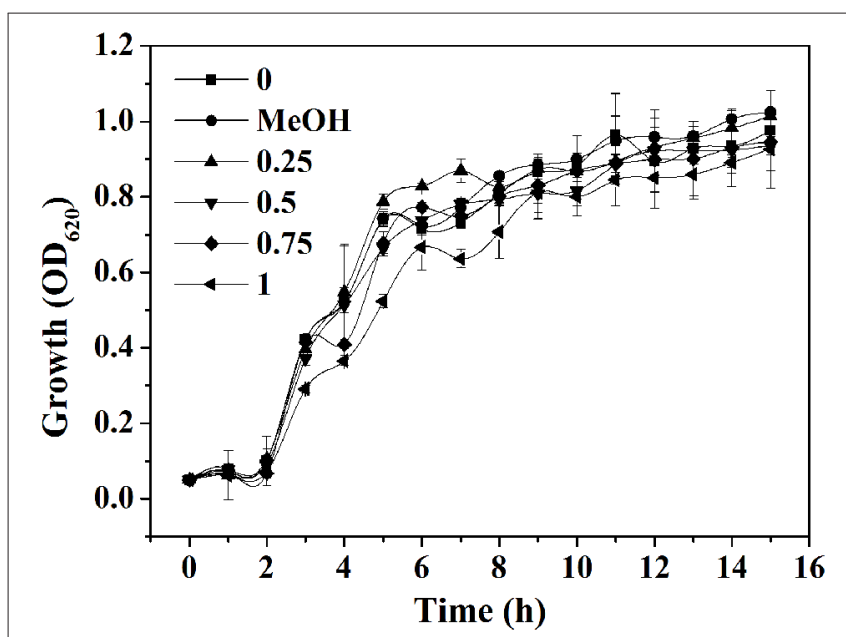

FIGURE 2 | Effect of $P$. cucumerina extract on $P$. aeruginosa PAO1 growth. Growth at different concentrations of extracts $(0.25,0.5,0.75$, and $1 \mathrm{mg} \mathrm{mL}^{-1}$ ) for $15 \mathrm{~h}$ in tube. Distilled water $(0)$ and $\mathrm{MeOH}$ served as negative controls. Error bars indicated the standard deviations of three measurements.
AHLs was presented in Figure 3C. P. cucumerina extract with the concentration of $0.25-1 \mathrm{mg} \mathrm{mL}^{-1}$ caused reduction of C4HSL by $\sim 22,61,57$, and $62 \%$, respectively comparing with the water control (Figure 3C). Further, a significant decrease was also observed in 3-oxo-C12-HSL after treatment with P. cucumerina extract from 0.25 to $1 \mathrm{mg} \mathrm{mL}^{-1}$ (Figure 3C). Overall, the data indicated that the anti-QS activity of $P$. cucumerina extract may be caused by interfering with the production of AHLs.

\section{Effect of $P$. cucumerina Extract on Biofilm Development}

As shown in Figure 4A, P. cucumerina extract inhibited biofilms formation in a concentration-dependent manner. Extract with the concentration of $0.5-1 \mathrm{mg} \mathrm{mL} \mathrm{mL}^{-1}$ showed potent effects, reducing the biomass of $\mathrm{PAO} 1$ strain by $\sim 80,84$, and $85 \%$, respectively. $\mathrm{MeOH}$ showed no effect on the biofilm biomass of PAO1 comparing with the distilled water $(0)$.

Since the formation of biofilm by $P$. aeruginosa is correlated with EPS (Kim and Park, 2013), the impact of extract on EPS production of $P$. aeruginosa PAO1 was evaluated. Figure 4B showed that extract exhibited concentrationdependent inhibitory activities against EPS and could reduce EPS production up to $46 \%$ at $1 \mathrm{mg} \mathrm{mL}^{-1}$.

Direct microscopic observations are recognized to provide useful information on biofilms. Thus, light microscopy and fluorescence microscope were employed. In the control experiment, where bacteria were not treated with extract, a thick coating of biofilms was detected (Figures 5Aa,b). As shown in Figure 5Ac, treatment with $0.25 \mathrm{mg} \mathrm{mL}-1$ of extract showed no significant reduction in the microbial attachment. However, extract with the concentrations of $0.5,0.75$, and $1 \mathrm{mg}$ $\mathrm{mL}^{-1}$ showed significant reduction in the microbial attachment to the glass surface compared to controls (Figures 5Ad-f). The above anti-biofilm activities were further confirmed by fluorescence microscope (Figure 5B). Fluorescence microscope images showed a scattered appearance of extract treated samples compared with the control. The cell clusters were rarely visible on account of poor cohesiveness.

\section{Effect of $P$. cucumerina Extract on Biofilm Disruption}

The biofilm disruption activity of $P$. cucumerina extract against PAO1 was measured employing a standard quantitative biofilm assay method (Ding et al., 2011). As shown in Figure 6A, the extract exhibited strong ability to disrupt the established biofilms when treated with $0.5-1 \mathrm{mg} \mathrm{mL}^{-1}$ extract. Biofilm biomass was reduced by $\sim 52 \%$ in the presence of $1 \mathrm{mg} \mathrm{mL}^{-1}$ of extract.

Furthermore, SEM also showed the efficacy of extract as potent biofilm disrupter. The images showed a scattered appearance after treatment with extract when compared with the control colonization (Figure 6B). The cells associated with the surface were almost scattered and the integrity of the biofilms was limited. SEM, a destructive method, relies on rigid sample preparation and may generate pseudo-positive or unexpected results. To circumvent this problem, samples were assayed employing fluorescence microscope after staining with acridine orange (Figure 6C), and the results were similar to SEM analysis. 


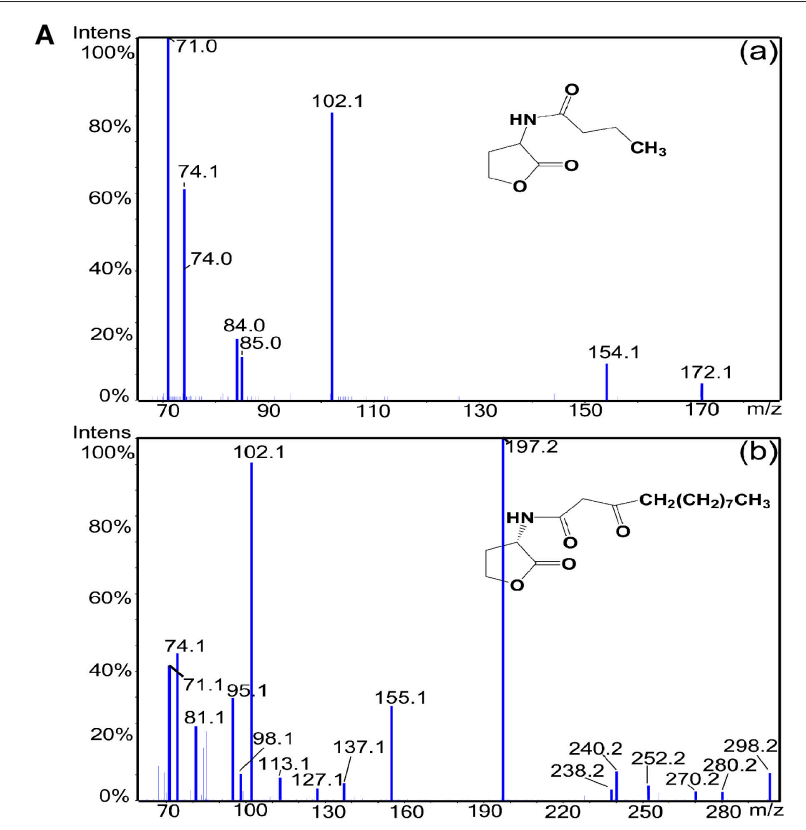

B
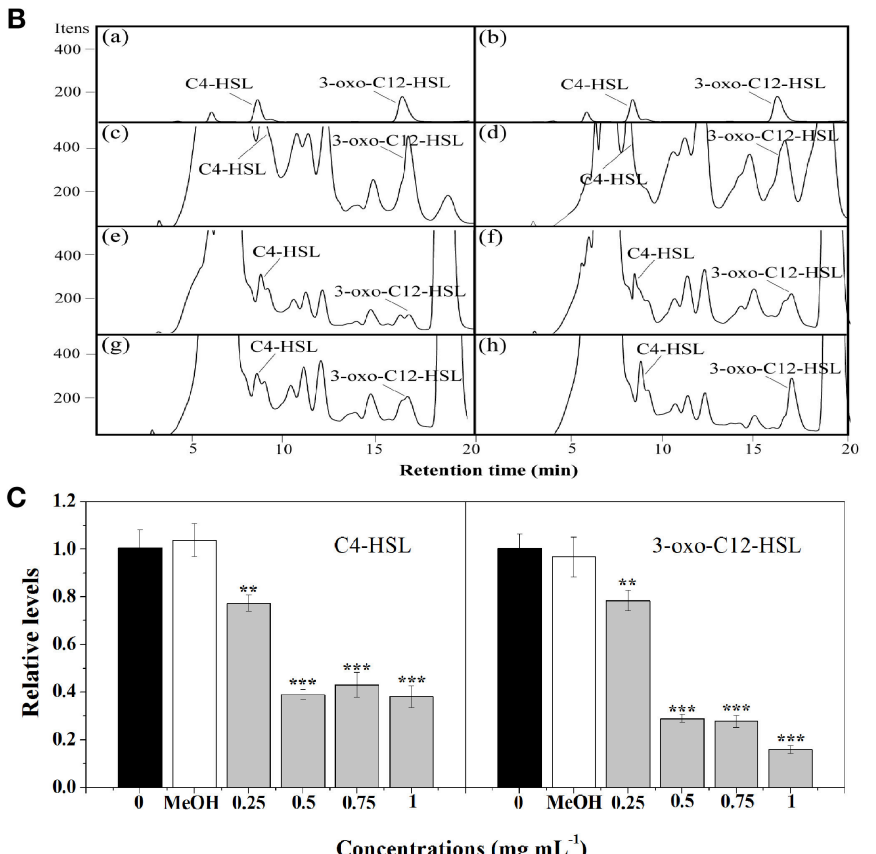

FIGURE 3 | Relative quantification of C4-HSL and 3-oxo-C12-HSL produced by $P$. aeruginosa using LC-MS/MS chromatograms. (A) MS/MS spectrum of (a) C4-HSL and (b) 3-oxo-C12-HSL. (B) HPLC chromatograms of C4-HSL and 3-oxo-C12-HSL present in the supernatant from P. aeruginosa cultures supplemented with (c) distilled water, (d) $\mathrm{MeOH}$, and (e-h) P. cucumerina extract $\left(0.25,0.5,0.75\right.$, and $\left.1 \mathrm{mg} \mathrm{mL}^{-1}\right)$. (a,b) Represented the standards of C4-HSL and 3-oxo-C12-HSL. (C) Quantitative assessment of C4-HSL and 3-oxo-C12-HSL treated with P. cucumerina extract $\left(0.25-1 \mathrm{mg} \mathrm{mL}^{-1}\right)$. Distilled water (0) and MeOH served as negative controls. Error bars indicated the standard deviations of three measurements. Statistically difference was determined by ANOVA followed by Tukey-Kramer test. ${ }^{\star \star} p<0.01$ vs. the water control $(0) .{ }^{\star \star \star} p<0.001$ vs. the water control (0).
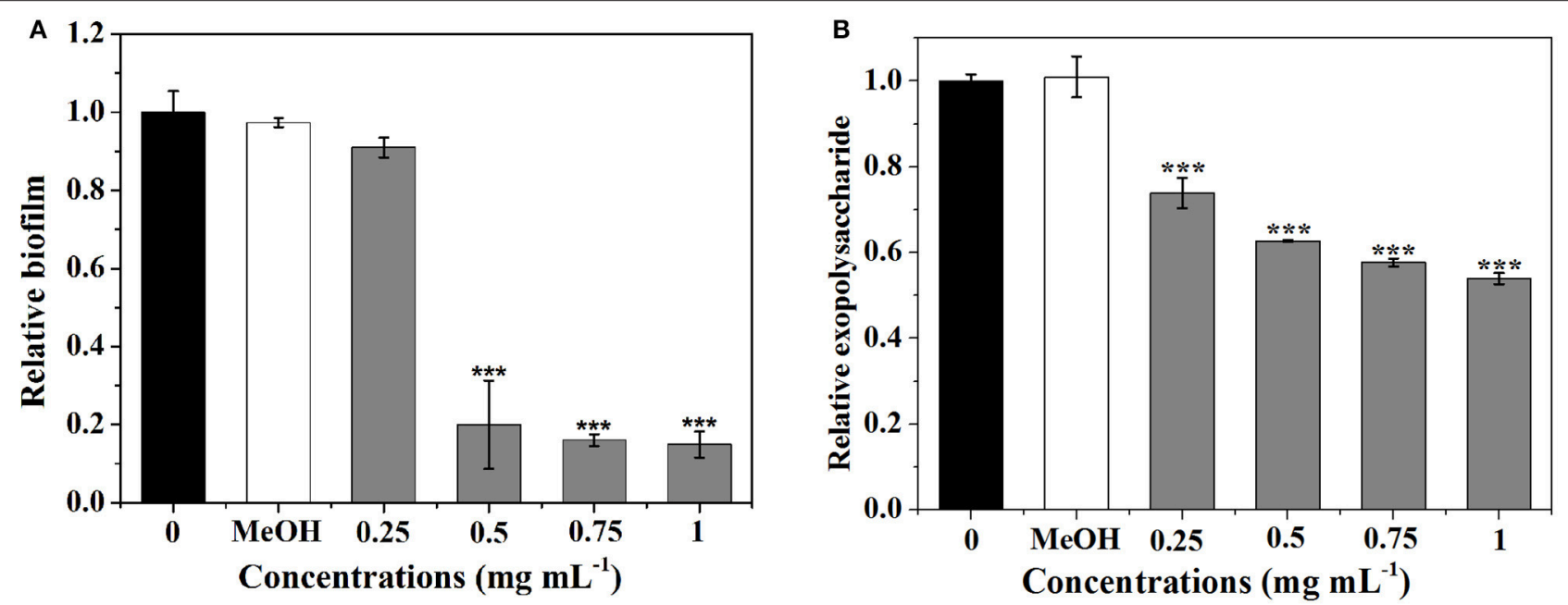

FIGURE 4 | Effects of $\boldsymbol{P}$. cucumerina extract on biofilm development and exopolysaccharide production. (A) Biofilm development and (B) exopolysaccharide production were quantified after $24 \mathrm{~h}$ of incubation by measuring at OD 570 and $490 \mathrm{~nm}$, respectively. Error bars indicated the standard deviations of three measurements. Statistically difference was determined by ANOVA followed by Tukey-Kramer test. ${ }^{* \star} p<0.001$ compared with the water control $(0)$.

\section{Analysis of the Production of Virulence Factors of $P$. aeruginosa}

Five virulence factors (protease, elastase, pyocyanin, rhamnolipid, and alginate) of $P$. aeruginosa were analyzed to evaluate the effects of extract on virulence (Figure 7). As shown in Figure 7A, the expression level of protease was significantly suppressed by 0.75 and $1 \mathrm{mg} \mathrm{mL} \mathrm{mL}^{-1}$ of extract. At $1 \mathrm{mg} \mathrm{mL}^{-1}, 27.3 \%$ inhibition of protease activities 
A
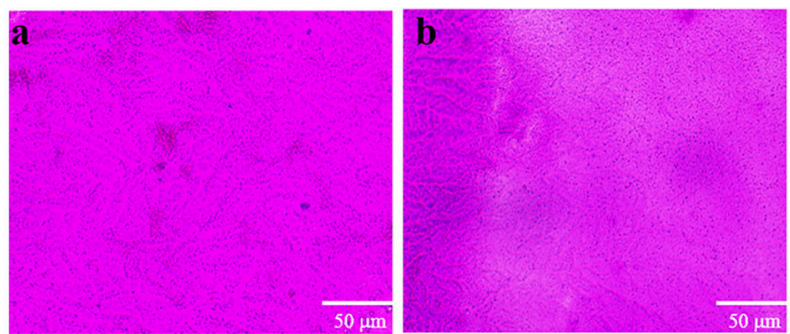

d
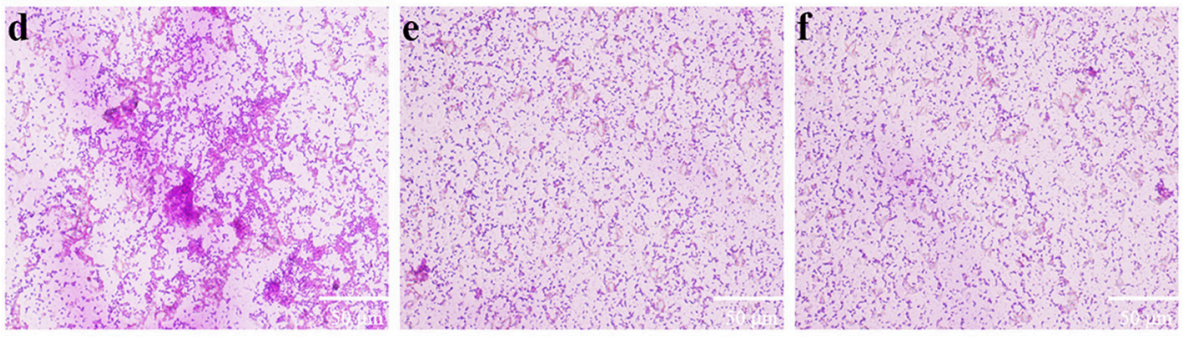

B
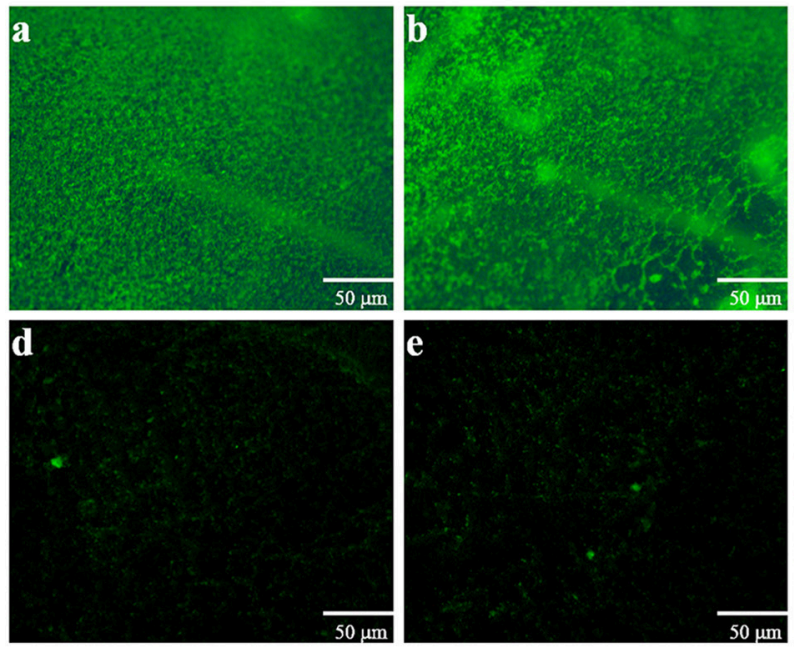
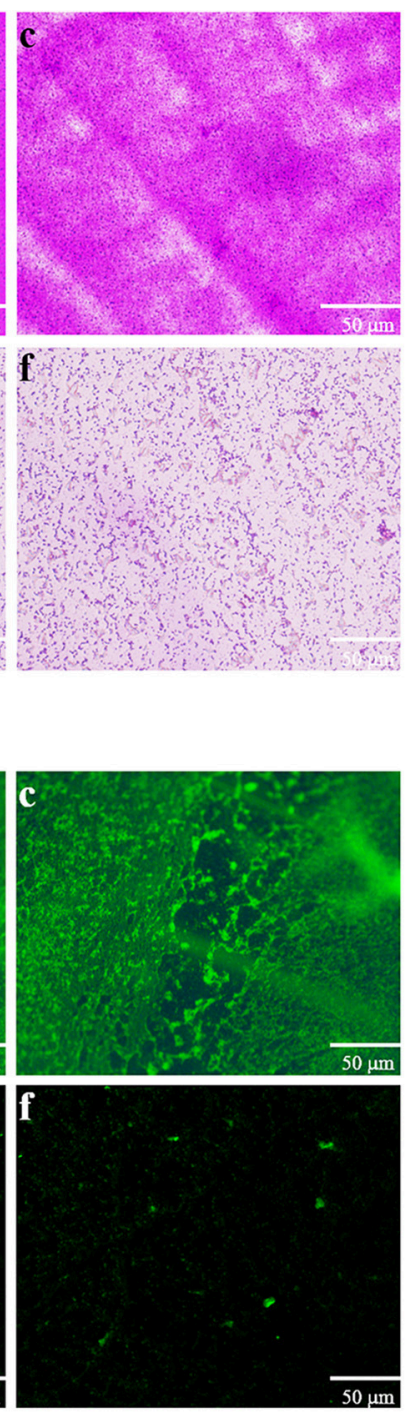

FIGURE 5 | Microscopic images of bacterial biofilms grown in the absence and presence of $\boldsymbol{P}$. cucumerina extract. (A) Light microscopic images and (B) fluorescence microscopic images of (a) distilled water, (b) $\mathrm{MeOH}$, and (c-f) extract $\left(0.25-1 \mathrm{mg} \mathrm{mL}^{-1}\right)$ treated biofilms of $P$. aeruginosa PAO1.

was observed. Production of elastase by $P$. aeruginosa is one of the QS-dependent behaviors (Husain et al., 2015). As shown in Figure $\mathbf{7 B}$, the reduction in elastase was concentration-dependent. Approximately 42\% inhibition in elastase was detected after treatment with extract at $1 \mathrm{mg} \mathrm{mL}^{-1}$.

Pyocyanin is a vital factor for infection and biofilm formation in $P$. aeruginosa (Wu et al., 2016). Figure 7C showed a significantly decreased production of pyocyanin treated with extract. At $0.25 \mathrm{mg} \mathrm{mL}^{-1}$, there was a $40 \%$ decrease in pyocyanin production and at $1 \mathrm{mg} \mathrm{mL} \mathrm{mL}^{-1}$, nearly $70 \%$ inhibition was observed. Furthermore, extract also exhibited concentrationdependent inhibitory activities against rhamnolipid and could reduce rhamnolipid production up to $50 \%$ at concentration of $1 \mathrm{mg} \mathrm{mL}^{-1}$ (Figure 7D).
As alginate is a constituent of the extracellular matrix of $P$. aeruginosa biofilms (Luo et al., 2016), the efficiency of extract to reduce the alginate production was determined. Results demonstrated that the alginate production was significantly reduced with increasing concentrations of extract. Approximately 52\% reduction was observed when exposure to extract at $1 \mathrm{mg} \mathrm{mL}^{-1}$ (Figure $7 \mathbf{E}$ ).

\section{Swarming and Swimming Inhibition Assay}

Swarming and swimming motility play important roles in QS-mediated biofilm formation in uropathogens (Jones et al., 2004). Inhibition of swarming and swimming motility was observed at concentrations as low as $0.25 \mathrm{mg} \mathrm{mL}^{-1}$ of extract (Figures 8Ac,Bc). P. aeruginosa PAO1 exhibited swarming motility with a total swarming diameter of $33 \mathrm{~mm}$. When treated 


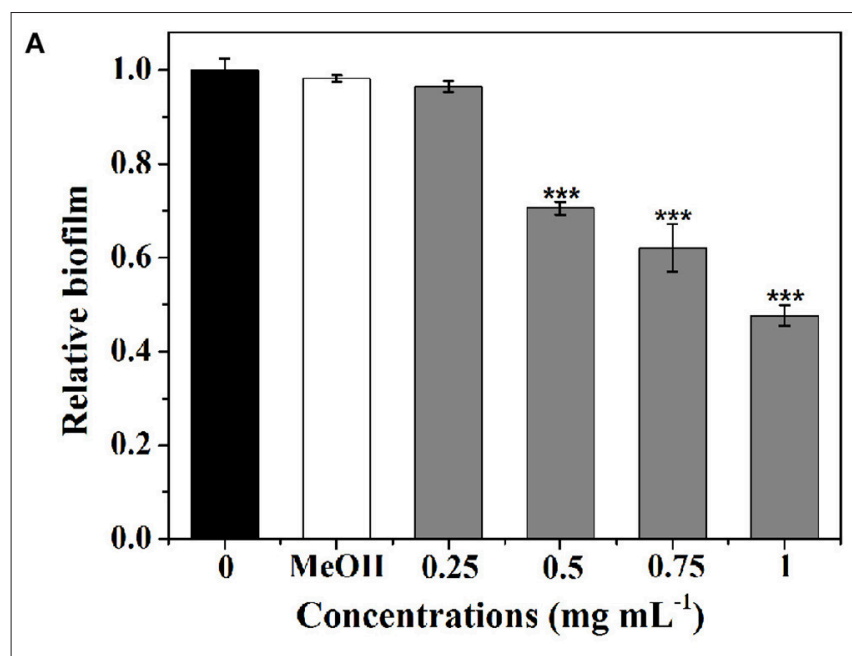

B
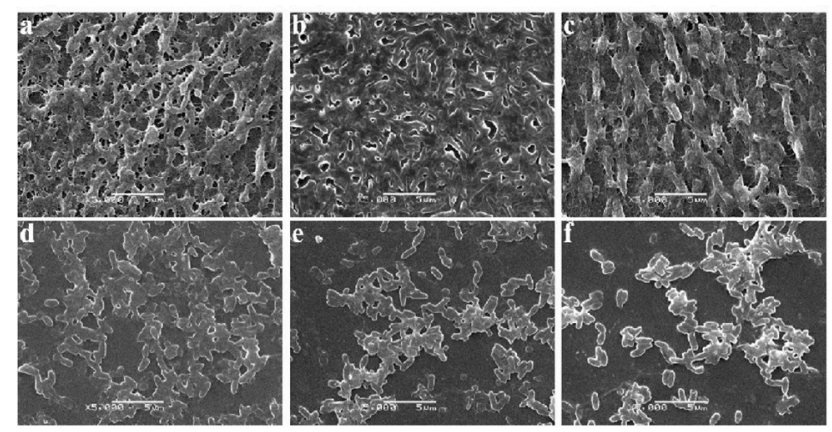

C
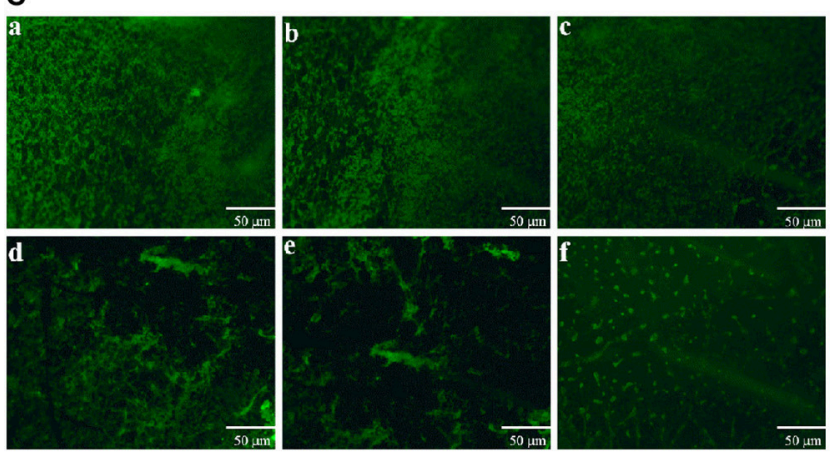

FIGURE 6 | Effect of $P$. cucumerina extract on biofilm disruption.

(A) Quantitative assessment of biofilm biomass disruption. Mean values of triplicate independent experiments and SD were shown. Statistically difference was determined by ANOVA followed by Tukey-Kramer test. ${ }^{\star * *} p<0.001$ compared with the controls ( $\mathrm{O}$ and $\mathrm{MeOH})$. (B) SEM images and (C) fluorescence microscopic images of (a) distilled water, (b) $\mathrm{MeOH}$, and (c-f) extract $\left(0.25-1 \mathrm{mg} \mathrm{mL}^{-1}\right)$ treated biofilms of $P$. aeruginosa PAO1. Scale bars $=5 \mu \mathrm{m}$.

with extract at concentrations ranging from 0.5 to $1 \mathrm{mg} \mathrm{mL}^{-1}$, bacteria could grow and form a colony in the center with a diameter not exceeding $12 \mathrm{~mm}$, and the tendril formation was also observed to be significantly reduced (Figures 8Ad-f) when compared with the negative controls (Figures 8Aa,b). Furthermore, similar results were observed in swimming motility as well (Figures $\mathbf{8 B a}-\mathbf{f}$ ).

\section{Thermal Stability of $\boldsymbol{P}$. cucumerina Extract}

In this study, thermal stability was measured by $10 \mathrm{~min}$ incubation of the extract at varying temperatures ranging from 30 to $95^{\circ} \mathrm{C}$, and then the anti-pyocyanin capacity of $P$. cucumerina extract was determined. Results shown in Figure S4 demonstrated that the $P$. cucumerina extract was relatively thermal stable. More than $90 \%$ activity of the extract was remained even after being maintained at $95^{\circ} \mathrm{C}$ for 10 min when compared to heat treatment at $30^{\circ} \mathrm{C}$.

\section{Potential Bioactive Compounds Contained in $P$. cucumerina Extract}

LC-MS/MS was employed to identify potential bioactive compounds in P. cucumerina extract (Figure 9A). As shown in Table 1, four compounds were identified. The extract ion chromatogram at $m / z 177.0556$ showed peak eluting at $5.87 \mathrm{~min}$. This peak displayed the fragment at $m / z 159\left(\mathrm{M}-\mathrm{H}-\mathrm{H}_{2} \mathrm{O}\right)$ and 131 (M-H- $\left.\mathrm{CH}_{2} \mathrm{O}_{2}\right)$ (Figure 9Ba). The spectrum was indicative of mellein (Zhang X. et al., 2016). Compound 2 yielded a quasimolecular ion $[\mathrm{M}-\mathrm{H}]^{-}$at $m / z 277.0718$ and fragment $\mathrm{MS}$ ions at $m / z 219\left(\mathrm{M}-\mathrm{H}-\mathrm{C}_{2} \mathrm{H}_{2} \mathrm{O}_{2}\right)$ and $191\left(\mathrm{M}-\mathrm{H}-\mathrm{C}_{3} \mathrm{H}_{2} \mathrm{O}_{3}\right)$ (Figure 9Bb), being identified as citreoisocoumarin. These fragments are in accordance with the same profile described by one previous study (Rasmussen et al., 2010). The extract ion chromatogram at $\mathrm{m} / \mathrm{z}$ 153.0194 in $P$. cucumerina extract showed a peak at $3.39 \mathrm{~min}$ (Table 1). This peak displayed the fragments at $m / z 109$ (M-H$\left.\mathrm{CO}_{2}\right)$ and $81\left(\mathrm{M}-\mathrm{H}-\mathrm{CH}_{2} \mathrm{O}_{3}\right)$ (Figure 9Bc). The spectrum data was consistent with that of patulin (Desmarchelier et al., 2011), which was further validated by a commercial standard patulin (Figure 9Be). Quantitation analysis showed that the production of patulin was $17.62 \mu \mathrm{g} \mathrm{mL}^{-1}$ of fungal extract $\left(1 \mathrm{mg} \mathrm{mL} \mathrm{mL}^{-1}\right)$ and this concentration was comparable with the production of $5.5 \mu \mathrm{g} \mathrm{mL}^{-1}$ of patulin present in fungal broth (Figure S5A). The extract ion chromatogram at $m / z 269.0454$ showed a peak at $13.18 \mathrm{~min}$. This peak displayed the fragments at $\mathrm{m} / z 241$ (M$\mathrm{H}-\mathrm{CO}), 225\left(\mathrm{M}-\mathrm{H}-\mathrm{CO}_{2}\right)$, and $197\left(\mathrm{M}-\mathrm{H}-\mathrm{CH}_{2} \mathrm{O}_{3}\right)$ (Figure 9Bd). This spectrum was indicative of emodin (Song et al., 2008), which was also further validated by a commercial standard emodin (Figure 9Bf). Further, the production of emodin was quantified by $20.37 \mu \mathrm{g} \mathrm{mL}^{-1}$ of fungal extract $\left(1 \mathrm{mg} \mathrm{mL}^{-1}\right)$ and this concentration was comparable with the production of $6.4 \mu \mathrm{g}$ $\mathrm{mL}^{-1}$ of emodin present in fungal broth (Figure S5B).

\section{Effect of the Four Compounds on $P$. aeruginosa Biofilms and Virulence Factors}

To screen the bioactive compounds responsible for the antibiofilm and antivirulence activities of P. cucumerina extract, four identified compounds above were tested. Unfortunately, mellein and citreoisocoumarin showed no anti-biofilm and antivirulence activities (Figure S6). Patulin has been reported to inhibit QS-controlled gene expression in $P$. aeruginosa PAO1 (Rasmussen et al., 2005). Apart from gene expression inhibition, could patulin inhibit QS regulated phenomena such as biofilms and production of virulence factors or not? In this study, the MIC of patulin was $100 \mu \mathrm{g} \mathrm{mL} \mathrm{m}^{-1}$. P. aeruginosa PAO1 treated with 25 and $50 \mu \mathrm{g} \mathrm{mL}^{-1}$ of patulin showed 

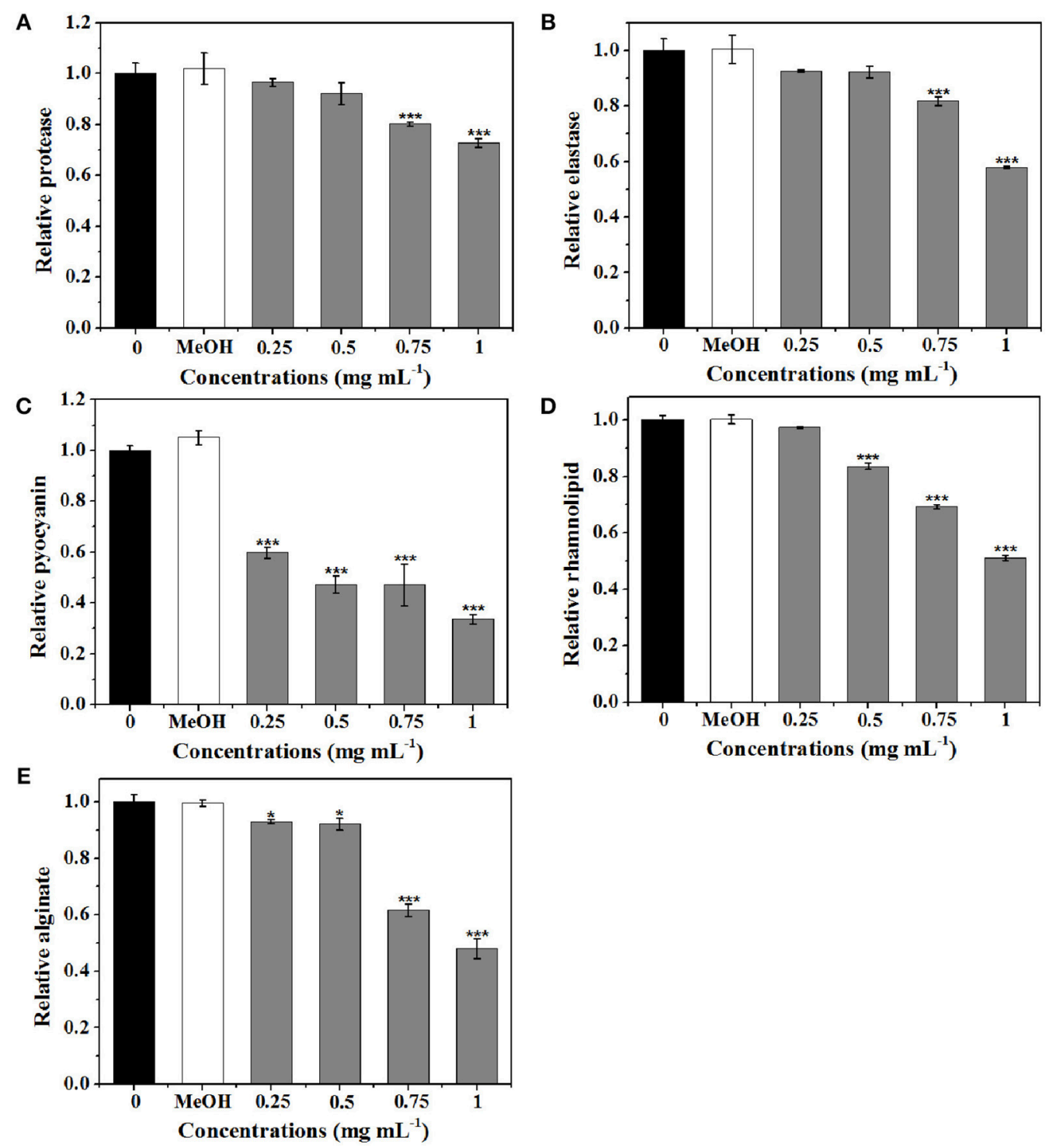

FIGURE 7 | Effects of $\boldsymbol{P}$ cucumerina extract on virulence factors production in $\boldsymbol{P}$, aeruginosa PAO1. Activities of virulence factors at different extract concentrations $\left(0.25,0.5,0.75\right.$, and $\left.1 \mathrm{mg} \mathrm{mL}^{-1}\right)$ were analyzed. Distilled water $(0)$ and $\mathrm{MeOH}$ served as negative controls. (A) Protease activity. (B) Elastase activity. (C) Pyocyanin activity. (D) Rhamnolipid activity. (E) Alginate activity. Error bars indicated the standard deviations of three measurements. Statistically difference was determined by ANOVA followed by Tukey-Kramer test. " $p<0.05$ vs. the water control $(0)$. ${ }^{* * *} p<0.001$ vs. the water control (0).

32 and $52 \%$ reduction in biofilm formation, respectively (Figure 10A). The above anti-biofilm activities were further confirmed by fluorescence microscope (Figures 10Be,f). A scattered appearance was observed when exposure to patulin. Patulin also owned strong ability to disperse the established biofilms. Approximately $44 \%$ reduction in biofilm biomass was detected after treatment with patulin at $50 \mu \mathrm{g} \mathrm{mL} \mathrm{mL}^{-1}$ (Figure 10C). SEM also showed the efficacy of patulin as an excellent biofilm disrupter, and a scattered appearance was observed in treated samples compared with the control colonization (Figures 10De,f). This is the first report of the biofilm disruption activity of patulin. To check the antivirulence effect of patulin on $P$. aeruginosa, virulence factors including protease, elastase, pyocyanin, and swimming were assayed since production of these factors was recognized as an indicator of active QS. Treatment with $50 \mu \mathrm{g} \mathrm{mL}^{-1}$ of patulin resulted in 31,62 , and $48 \%$ inhibition of protease, elastase, and pyocyanin, respectively (Figures 10E,F,H) without affecting cell growth (Figure 10H). Motility behavior was assessed by the swimming motility assay. Treated cells of $P$. aeruginosa showed shorter diameters on agar plates compared to the untreated controls (Figure 10I).

Emodin was another component identified in P. cucumerina extract by LC-MS/MS. We presumed that emodin might be another principal component for anti-biofilm and antivirulence in P. cucumerina extract. To validate this hypothesis, emodin 


\section{A}
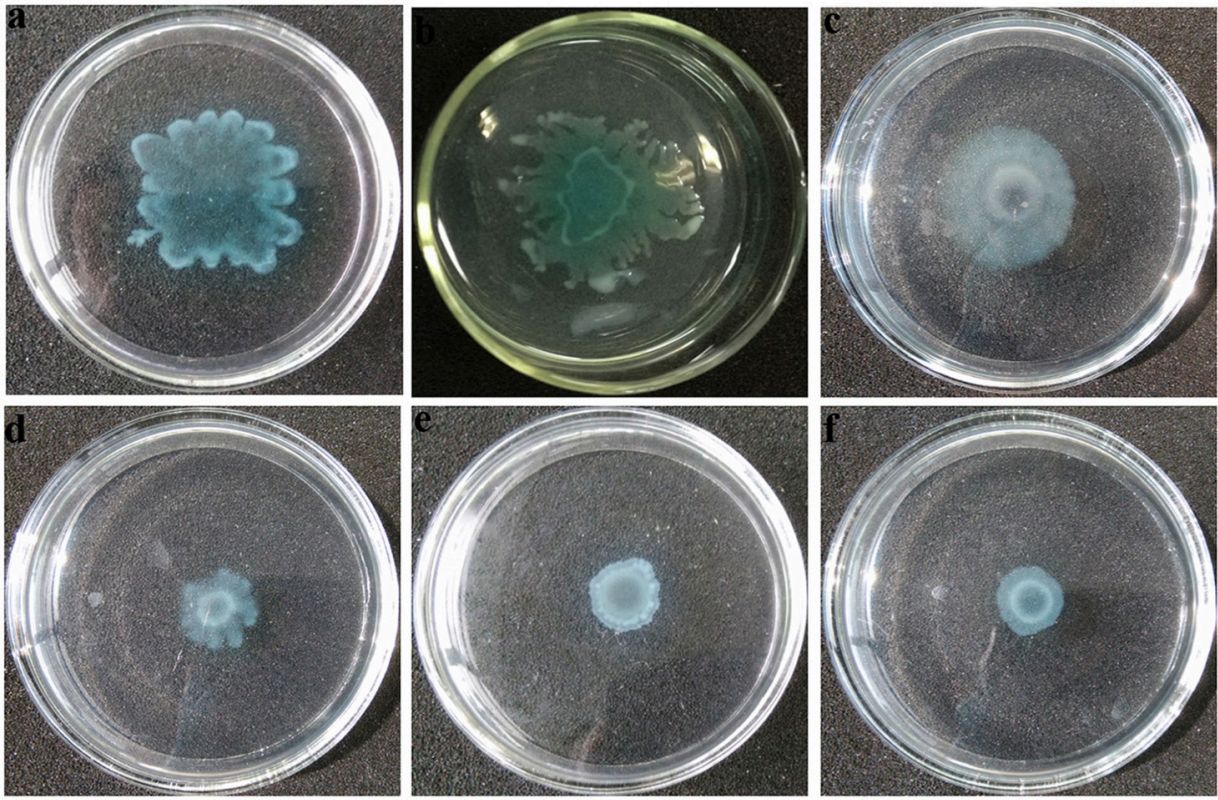

B
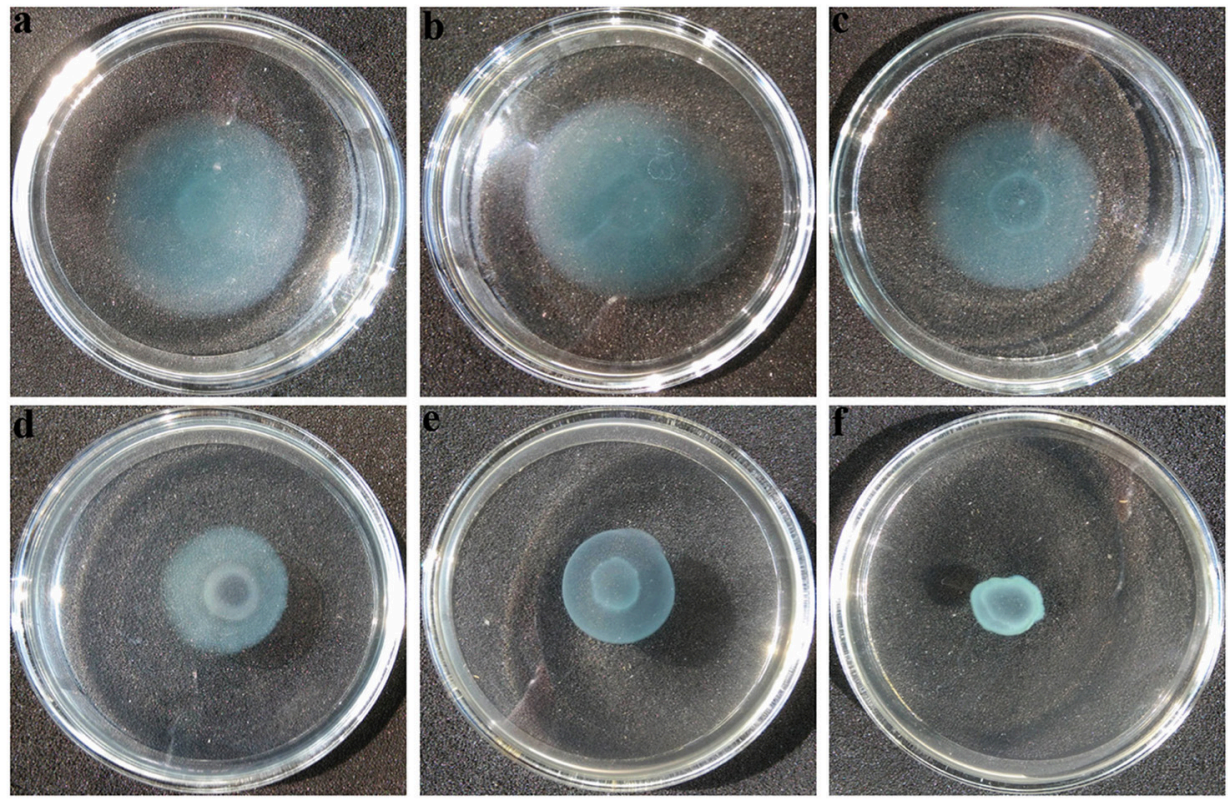

FIGURE 8 | Motility inhibition assays of $\boldsymbol{P}$. aeruginosa PAO1. (A) Swarming and (B) swimming motility assays were performed on plates containing different concentrations of agar in the absence or presence of $P$. cucumerina extract. (a), treated with distilled water; (b), treated with $\mathrm{MeOH}$; (c-f), treated with $0.25-1 \mathrm{mg}$ $\mathrm{mL}^{-1}$ extract. The results shown were representative of results from three independent experiments.

with concentrations of 25 and $50 \mu \mathrm{g} \mathrm{mL}^{-1}$ (MIC was $94 \mu \mathrm{g}$

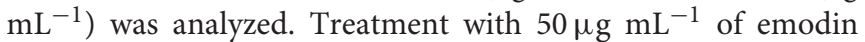
showed a $45 \%$ reduction in biofilm formation (Figure 10A). The above anti-biofilm activities of emodin were further confirmed by fluorescence microscope (Figures $10 B c, d$ ) comparing with the negative controls (Figures 10Ba,b). Biofilm disruption assay demonstrated that emodin $\left(50 \mu \mathrm{g} \mathrm{mL}^{-1}\right)$ treatment led to a $32 \%$ reduction in biofilm biomass (Figure 10C). SEM also revealed that biofilm formation decreased with the concentration of $50 \mu \mathrm{g}$ $\mathrm{mL}^{-1}$ of emodin as compared to the controls (Figure 10D). The treated bacteria were in the discrete form rather than in a group. In addition, $P$. aeruginosa dosed with $50 \mu \mathrm{g} \mathrm{mL}^{-1}$ of emodin resulted in 23,44 , and $50 \%$ inhibition of protease, elastase, and pyocyanin, respectively (Figures 10E-G). Emodin 


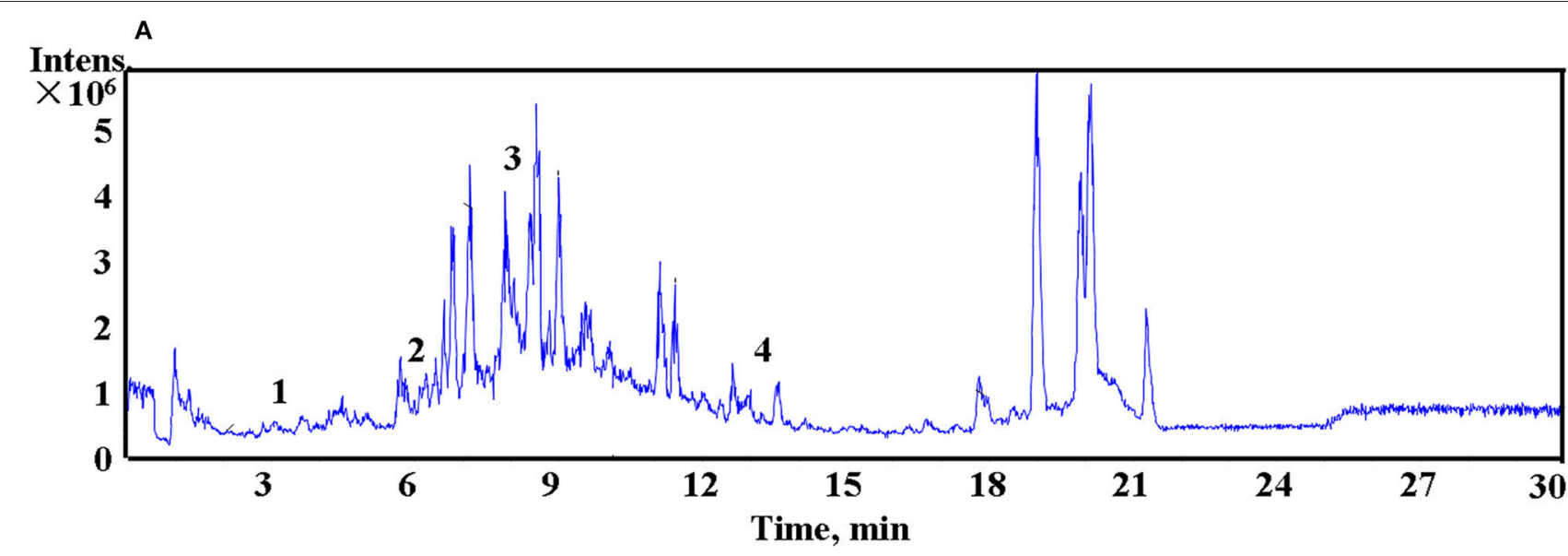

B

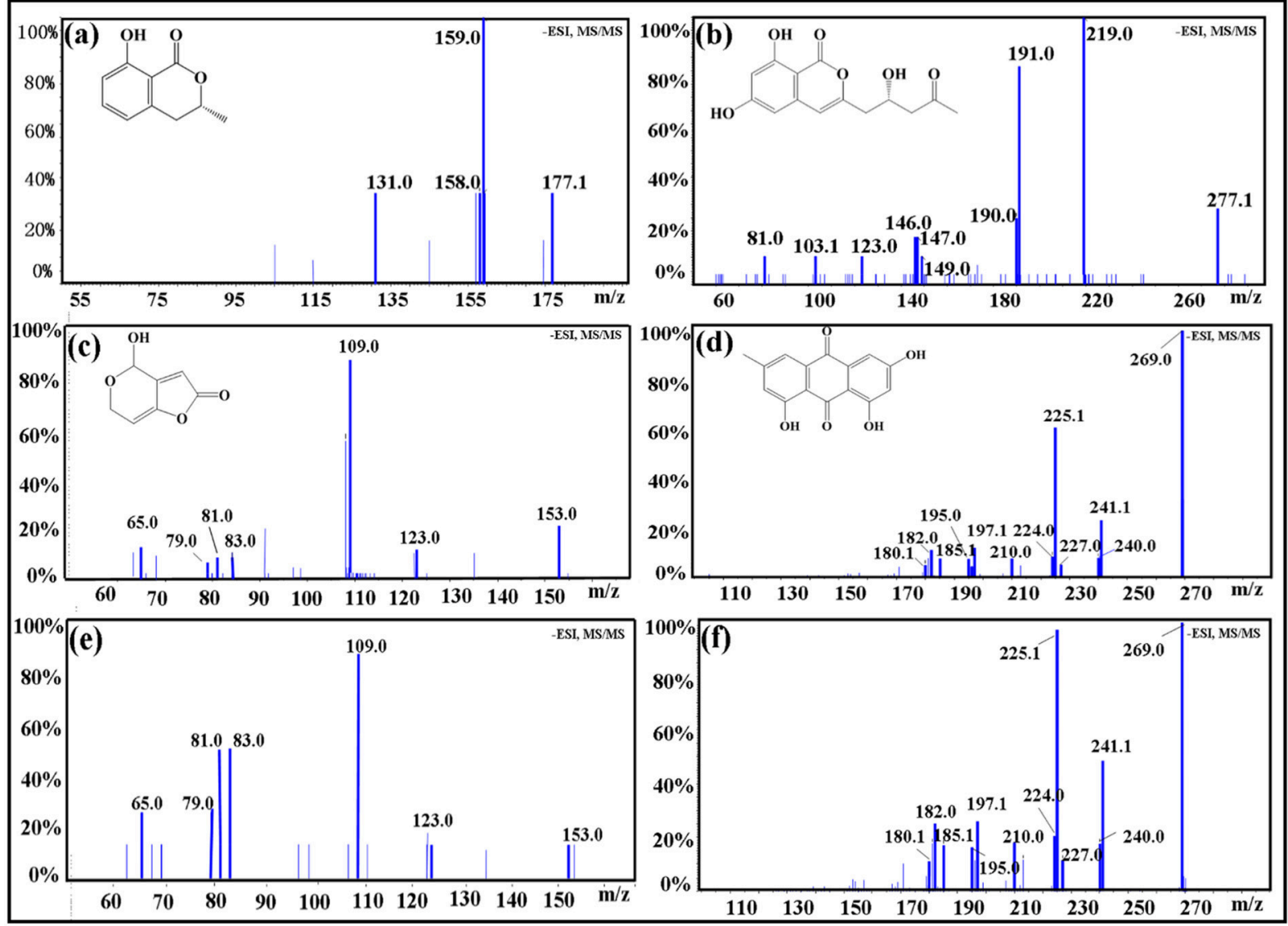

FIGURE 9 | (A) The total ion chromatogram of $P$. cucumerina extract. Peak numbers correspond to chemical compounds presented in Table 1. (B) Spectra of ion fragments obtained from analysis of $P$. cucumerina extract and standard samples of emodin and patulin. Analysis performed by using ESI in negative ion mode. Ion fragments correspond to chemical compounds presented in Table 1. (a) MS/MS spectrum of mellein; (b) MS/MS spectrum of citreoisocoumarin; (c) MS/MS

spectrum of patulin; (d) MS/MS spectrum of emodin; (e) MS/MS spectrum of a commercial standard patulin; (f) MS/MS spectrum of a commercial standard emodin.

treatment with the concentration of $50 \mu \mathrm{g} \mathrm{mL} \mathrm{m}^{-1}$ had no significantly inhibitory effect on cell growth comparing with the $\mathrm{MeOH}$ control but significantly with the water control (Figure 10H). To further confirm the data, the growth assay was performed again. The results showed that emodin with the concentration of $50 \mu \mathrm{g} \mathrm{mL} \mathrm{m}^{-1}$ had no inhibitory effect on $P$. aeruginosa growth comparing with both the negative controls (Figure S7). Swimming motility was also significantly inhibited after treatment with 25 and $50 \mu \mathrm{g} \mathrm{mL}^{-1}$ of emodin (Figures 10Ic,d). 


\begin{tabular}{|c|c|c|c|c|c|c|c|}
\hline Peak & $\mathbf{R}_{\mathbf{t}} / \mathrm{min}$ & Molecular formula & Tentative identification & Calculated $[\mathrm{M}-\mathrm{H}]^{-}$ & Measured $[\mathrm{M}-\mathrm{H}]^{-}$ & Error/ppm & $\mathrm{MS}^{2}$ \\
\hline 1 & 3.39 & $\mathrm{C}_{7} \mathrm{H}_{6} \mathrm{O}_{4}$ & Patulin & 153.0193 & 153.0194 & 0.7 & 109,81 \\
\hline 2 & 5.87 & $\mathrm{C}_{10} \mathrm{H}_{10} \mathrm{O}_{3}$ & Mellein & 177.0557 & 177.0556 & -0.8 & 159,131 \\
\hline 3 & 7.94 & $\mathrm{C}_{14} \mathrm{H}_{14} \mathrm{O}_{6}$ & Citreoisocoumarin & 277.0718 & 277.0718 & 0.1 & 219,191 \\
\hline 4 & 13.18 & $\mathrm{C}_{15} \mathrm{H}_{10} \mathrm{O}_{5}$ & Emodin & 269.0456 & 269.0454 & -0.6 & $241,225,197$ \\
\hline
\end{tabular}

Overall, the observed inhibition of $P$. aeruginosa biofilm and virulence factors suggested that patulin and emodin might act as the principal active components in P. cucumerina extract.

\section{DISCUSSION}

It is reported that nearly $80 \%$ of human infections are induced by biofilms (Ricucci and Siqueira, 2010). Biofilms are microbial communities that are closely associated with antibiotic resistance (Michalska and Wolf, 2015; Vadekeetil et al., 2016). Therefore, the exploration of natural compounds that could attenuate pathogenicity rather than cell growth has aroused great attention. Previous studies demonstrated that fungal metabolites were able to interfere with QS communication and/or attenuate QSassociated processes including biofilm formation or virulence factors secretion (Rasmussen et al., 2005; Wang et al., 2011). Recently, some anti-QS compounds secreted by an endophytic fungus Penicillium restrictum have been reported (Figueroa et al., 2014). However, no literature about the phyllosphere fungi with anti-biofilm and anti-quorum sensing activities has been reported to the best of our knowledge. In this study, a phyllosphere fungus was isolated from $O$. violaceus and identified as $P$. cucumerina. The metabolites of $P$. cucumerina could effectively reduce the AHLs production, biofilm formation and virulence factors of $P$. aeruginosa. The metabolites could also disrupt the preformed biofilms.

It is known that $P$. aeruginosa uses AHLs as QS signal to coordinate the expression of disease-causing attributes, such as motility, virulence factors secretion, and biofilm formation (Chan et al., 2015). Biofilm persistence is attributed to a matrix made up of EPS, lipids, and proteins (Flemming and Wingender, 2010). EPS serves as a protective barrier that could block the entry of antibiotics into cells (Fux et al., 2005). EPS secretion of $P$. aeruginosa PAO1 is controlled by QS systems (Nadell et al., 2008). Presently, a remarkable decrease of AHLs and EPS was detected in $P$. aeruginosa PAO1 with extract treatment. Along with the anti-biofilm characteristic, we speculated that $P$. cucumerina extract might inhibit the biofilm formation via interfering with the synthesis of AHLs, then inhibiting the formation of EPS, which is vital for biofilm formation and stability.

An additional remarkable characteristic of extract is its capacity of disrupting the preformed biofilms. Several polysaccharides have been reported to trigger biofilms dispersal (Rendueles et al., 2013). Mechanisms in the biofilm disruption have been proposed, including cell death, induction of cellular motility, and matrix-degrading enzymes (Karatan and Watnick, 2009; Kaplan, 2010). In spite of researches on the mechanisms of action of anti-biofilm compounds, the precise mechanisms are yet to be clarified (Rendueles et al., 2013). Therefore, it is attractive to uncover the detailed anti-biofilm mechanisms of extract in the future.

$P$. aeruginosa produces diverse virulence factors which are under the control of QS (Wu et al., 2014). We investigated the production of protease, elastase, pyocyanin, rhamnolipid, and alginate in the presence of $P$. cucumerina extract, and found that production of these factors were significantly reduced by $P$. cucumerina extract. Additionally, the effect of P. cucumerina extract on $P$. aeruginosa PAO1 was further determined by performing assays for motility. The swimming and swarming motilities of $P$. aeruginosa PAO1 were effectively reduced in the presence of $P$. cucumerina extract.

To understand the bioactive component of $P$. cucumerina extract, four metabolites mellein, citreoisocoumarin, patulin, and emodin were identified by LC-MS/MS. Mellein is an anthraquinone mycotoxin that was produced by Penicillium islandicum (Kawai et al., 1984). In this study, mellein showed no antivirulence or anti-biofilm capacities. Recently, coumarin was reported to possess antivirulence and anti-biofilm capacities against $P$. aeruginosa (Gutiérrez-Barranquero et al., 2015). Citreoisocoumarin, one coumarin analog, showed no antivirulence or anti-biofilm capacities in this study. The results suggested that the changes to the structural motif can influence the antivirulence efficacy. Apart from mullein and citreoisocoumarin, patulin and emodin showed potent antivirulence and anti-biofilm capacities at concentrations of 25 and $50 \mu \mathrm{g} \mathrm{mL}^{-1}$. Quantification analysis showed that the production of patulin and emodin were 17.62 and $20.37 \mu \mathrm{g} \mathrm{mL}^{-1}$ of fungal extract $\left(1 \mathrm{mg} \mathrm{mL} \mathrm{m}^{-1}\right)$, respectively. The productions were lower than the concentrations $\left(25\right.$ and $50 \mu \mathrm{g} \mathrm{mL}^{-1}$ ) used in this study. These results suggested that P. cucumerina extract may contain other antivirulence and anti-biofilm compounds besides patulin and emodin.

In conclusion, this study clearly demonstrated that $P$. cucumerina extract not only inhibits virulence factors and biofilm formation, but also disrupt the preformed biofilms of $P$. aeruginosa PAO1. This is the first report of an antivirulence and anti-biofilm $P$. cucumerina from the phyllosphere of $O$. violaceus. The LC-MS/MS analysis further confirmed two antivirulence compounds patulin and emodin. All in all, this study provides fascinating new pathways for screening antipathogenic agents from phyllosphere fungus. It is not doubt that other antibiofilm and antivirulence compounds should be presented in $P$. cucumerina, we will try to isolate such compounds in the near future. 


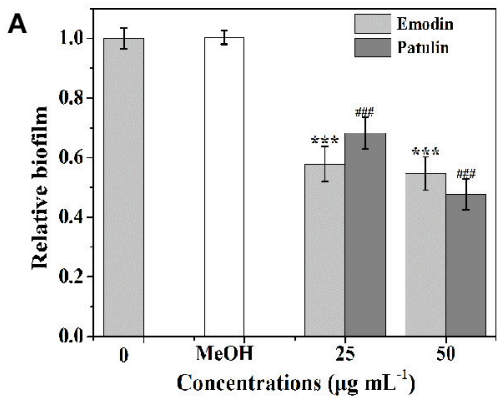

B
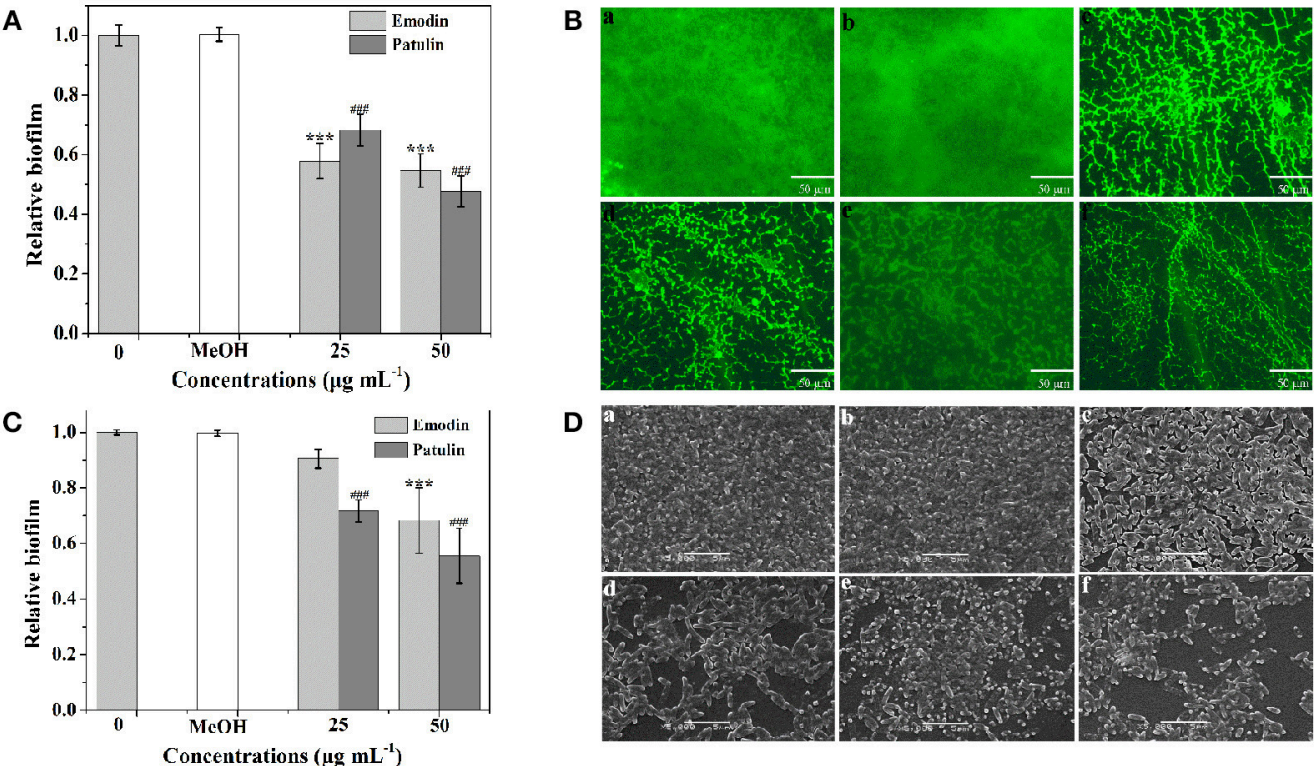

D

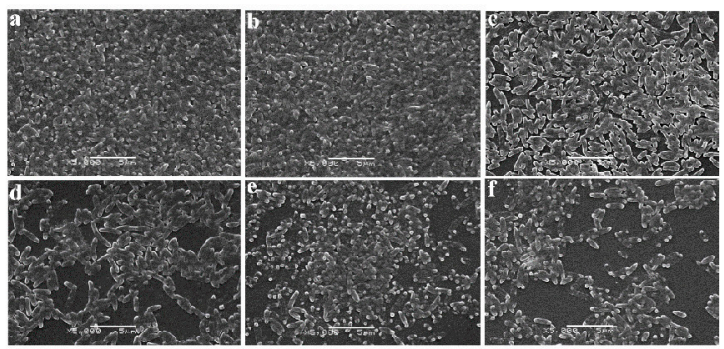

E

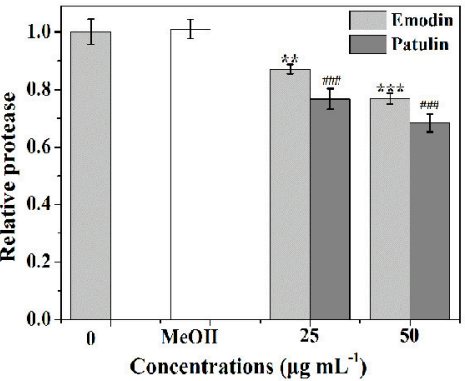

$\mathbf{F}$

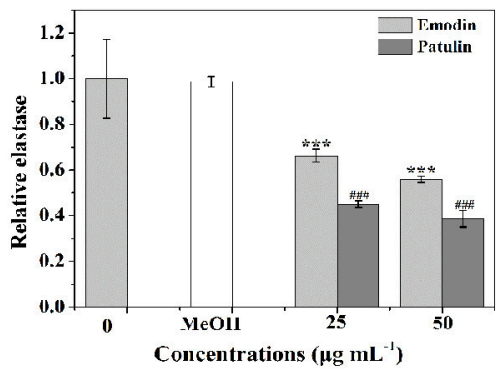

G
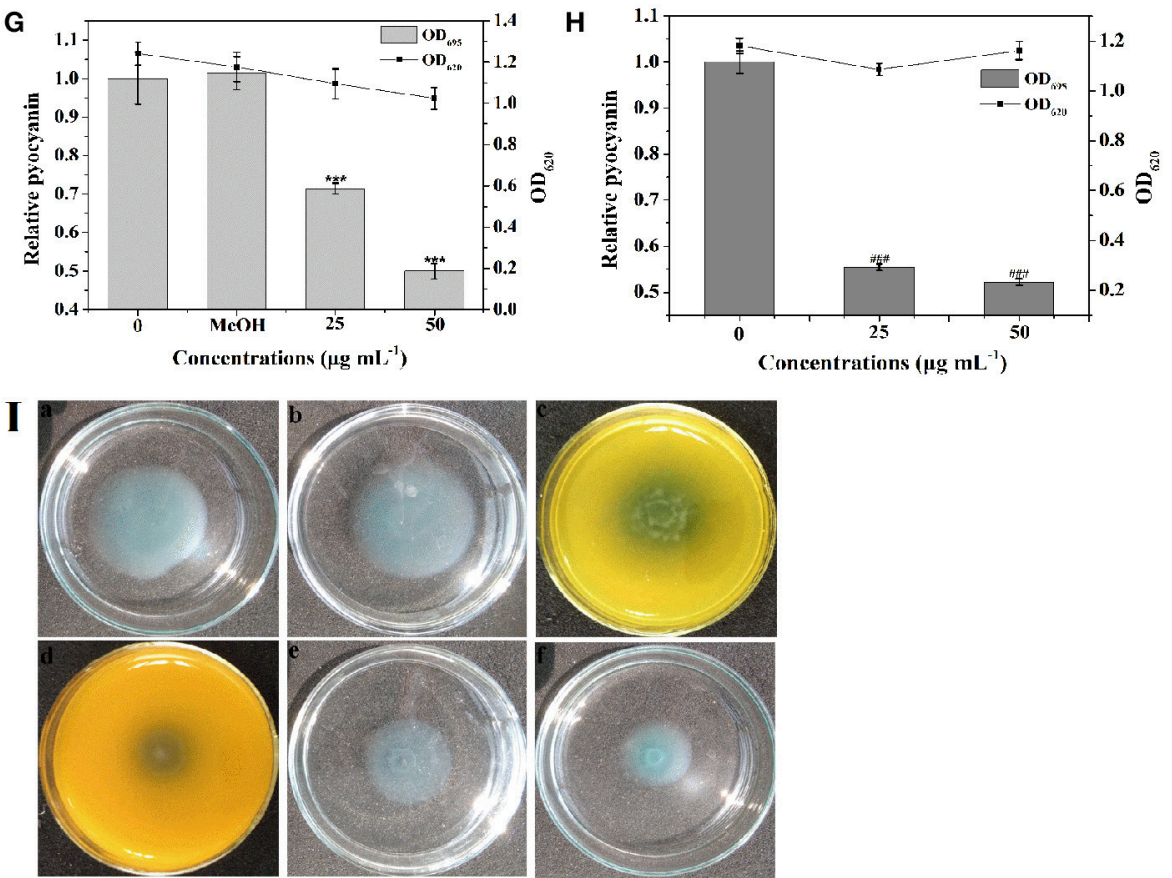

FIGURE 10 | Effects of emodin (25 and $50 \mu \mathrm{g} \mathrm{mL}^{-1}$ ) and patulin (25 and $50 \mu \mathrm{g} \mathrm{mL}^{-1}$ ) on biofilm development and virulence factors. (A) Biofilm development was quantified after $24 \mathrm{~h}$ of incubation by measuring at OD 570. (B) Fluorescence microscopic images of (a) distilled water, (b) MeOH, (c,d) emodin (25 


\section{FIGURE 10 | Continued}

and $50 \mu \mathrm{g} \mathrm{mL}^{-1}$, respectively), and (e,f) patulin $\left(25\right.$ and $50 \mu \mathrm{g} \mathrm{mL}^{-1}$, respectively) treated biofilms of $P$. aeruginosa PAO1. (C) Quantitative assessment of biofilm biomass disruption. (D) SEM images of (a) distilled water, (b) $\mathrm{MeOH}, \mathbf{( c , d )}$ emodin $\left(25\right.$ and $50 \mu \mathrm{g} \mathrm{mL}^{-1}$, respectively), and (e,f) patulin $\left(25 \mathrm{and}_{50 \mu \mathrm{g} \mathrm{mL}}^{-1}\right.$, respectively) treated biofilms of $P$. aeruginosa PAO1. Scale bars $=5 \mu \mathrm{m}$. (E) Protease activity. (F) Elastase activity. (G) Effects of emodin on pyocyanin production of $P$. aeruginosa PAO1. (H) Effects of patulin on pyocyanin production of $P$. aeruginosa PAO1. (I) Swimming motility assays were performed on plates in the presence of (a) distilled water, (b) $\mathrm{MeOH},(\mathbf{c}, \mathbf{d})$ emodin $\left(25\right.$ and $50 \mu \mathrm{g} \mathrm{mL}^{-1}$, respectively), and (e,f) patulin (25 and $50 \mu \mathrm{g} \mathrm{mL}^{-1}$, respectively). Error bars indicated the standard deviations of three measurements. Statistically difference was determined by ANOVA followed by Tukey-Kramer test. ${ }^{\star \star} p<0.01$ vs. the water control (0). ${ }^{\star \star \star} p<0.001$ vs. the controls $(0$ and $\mathrm{MeOH})$. $\# \# \# p<0.001$ vs. the control (0).

\section{AUTHOR CONTRIBUTIONS}

$\mathrm{JZ}$ and $\mathrm{AJ}$ conceived and designed the experiments. JZ, SB, and TC performed the experiments. JZ, HC, RY, ML, and YF analyzed the data. JZ and AJ wrote the paper.

\section{FUNDING}

This work was supported by the grants from the National High Technology Research and Development Program of China (863 Program) (2014AA022208), Six Talent Peaks Project in Jiangsu Province, and the Fundamental Research Funds for the Central Universities (30916011307), the National Natural Science Foundation of China (31170131).

\section{ACKNOWLEDGMENTS}

The authors thank Yajun Xue, Nanjing Institute of Technology, Nanjing, China for his support in the scanning electron microscope analysis. The authors express their sincere thanks to Dr. Yuan Xu for providing important suggestions. The authors also thank Sangon Biotech, China for strain sequencing and identification.

\section{SUPPLEMENTARY MATERIAL}

The Supplementary Material for this article can be found online at: http://journal.frontiersin.org/article/10.3389/fmicb. 2017.00769/full\#supplementary-material

Table S1 | $p$-values of extract treatment compared with water control group using ANOVA Tukey-Kramer test.

Table S2 | $p$-values of extract treatment compared with $\mathrm{MeOH}$ control group using ANOVA Tukey-Kramer test.

\section{REFERENCES}

Bai, G. H., and Shaner, G. (1996). Variation in Fusarium graminearum and cultivar resistance to wheat scab. Plant Dis. 80, 975-979. doi: 10.1094/PD-80-0975

Carlucci, A., Raimondo, M. L., Santos, J., and Phillips, A. J. (2012). Plectosphaerella species associated with root and collar rots of horticultural crops in southern Italy. Persoonia 28, 34-48. doi: 10.3767/003158512X638251

Chan, K. G., Liu, Y. C., and Chang, C. Y. (2015). Inhibiting N-acyl-homoserine lactone synthesis and quenching Pseudomonas quinolone quorum sensing to attenuate virulence. Front. Microbiol. 6:1173. doi: 10.3389/fmicb.2015. 01173.

Clinical and Laboratory Standards Institute (CLSI) (2015). Methods for Dilution Antimicrobial Susceptibility Tests for Bacteria that Grow Aerobically; Approved Standard 10th Edition, M07-A10. Wayne, PA: CLSI.
Figure S1 | Anti-QS activities of 7 kinds of fungi using $A$. tumefaciens KYC55 as a reporter strain. A white halo around the well against a blue background was an indication of anti-QS zone. Overnight cultures of KYC55 $\left(1 \mathrm{~mL}, \mathrm{OD}_{620} \approx 0.7\right.$ ) were aliquoted into $100 \mathrm{~mL}$ of warm molten AT agar medium $\left[1.05 \% \mathrm{~K}_{2} \mathrm{HPO}_{4}, 0.45 \% \mathrm{KH}_{2} \mathrm{PO}_{4}, 0.02 \% \mathrm{MgSO}_{4} \cdot 7 \mathrm{H}_{2} \mathrm{O}, 0.0005 \%\right.$ $\mathrm{FeSO}_{4} \cdot 7 \mathrm{H}_{2} \mathrm{O}, 0.001 \% \mathrm{CaCl}_{2}, 0.0002 \% \mathrm{MnCl}_{2}, 0.2 \%\left(\mathrm{NH}_{4}\right)_{2} \mathrm{SO}_{4}, 0.2 \%$ D-mannitol, $0.8 \%$ agar, $\mathrm{pH} 7.2$, autoclaved at $115^{\circ} \mathrm{C}$ for $15 \mathrm{~min}$ ] and supplemented with $200 \mu \mathrm{L}$ X-gal ( $50 \mu \mathrm{g} \mathrm{mL}^{-1}$, Sigma-Aldrich, USA) and $5 \mu \mathrm{M}$ $\mathrm{N}$-(3-oxooctanoyl)-L-homoserine lactone (Sigma-Aldrich, USA) and then gently mixed. The mixture was poured immediately over the surface of a solidified AT agar plate as an overlay. Wells of $5 \mathrm{~mm}$ in diameter were made on each plate. Finally, the fungal extract $(10 \mu \mathrm{L})$ was added to the wells and the plates were incubated at $30^{\circ} \mathrm{C}$ for $24 \mathrm{~h}$.

Figure S2 | Colony morphology of $\boldsymbol{P}$ cucumerina B-JW-304. (a) Colony on PDA after 14 d at $24^{\circ} \mathrm{C}$. (b) Hyphal coil. (c,d) Septate conidia. Scale bars = $100 \mu \mathrm{m}$.

Figure S3 | Effects of $P$. cucumerina extract $\left(1 \mathrm{mg} \mathrm{mL}^{-1}\right)$ on $P$. aeruginosa PA01 growth. (A) Bacterial colonies of $P$. aeruginosa PAO1 (10 7 fold dilution) after incubation for $24 \mathrm{~h}$. (a) Distilled water control; (b) MeOH control; (c) P. cucumerina extract $\left(1 \mathrm{mg} \mathrm{mL}^{-1}\right.$ ) treatment. (B) Bacterial colonies number of $P$. aeruginosa PAO1 after incubation for $24 \mathrm{~h}$ with (0) distilled water, $\mathrm{MeOH}$ and $1 \mathrm{mg} \mathrm{mL}^{-1}$ of extract treatment. Error bars indicated the standard deviations of three measurements.

Figure S4 | Activity analysis of $\boldsymbol{P}$ cucumerina extract that was pretreated with heat $\left(30-95^{\circ} \mathrm{C}\right)$ by using pyocyanin as evaluation index. Error bars indicated the standard deviations of three measurements. ${ }^{* * *} p<0.001$ vs. the control (0)

Figure S5 | Standard curves targeting patulin (A) and emodin (B) for quantification.

Figure S6 | Anti-pyocyanin (A) and anti-biofilm (B) activities of mullein and citreoisocoumarin. Error bars indicated the standard deviations of three measurements.

Figure S7 | Effect of emodin on P. aeruginosa PAO1 growth. Growth at concentrations of emodin ( 25 and $50 \mu \mathrm{g} \mathrm{mL}^{-1}$ ) for $17 \mathrm{~h}$ in tube. Distilled water (0) and $\mathrm{MeOH}$ served as negative controls. Error bars indicated the standard deviations of three measurements.

Cycoń, M., Borymski, S., Żołnierczyk, B., and Piotrowska-Seget, Z. (2016). Variable effects of non-steroidal anti-inflammatory drugs (NSAIDs) on selected biochemical processes mediated by soil microorganisms. Front. Microbiol. 7:1969. doi: 10.3389/fmicb.2016.01969

Davies, D. G., Parsek, M. R., Pearson, J. P., Iglewski, B. H., Costerton, J. W., and Greenberg, E. P. (1998). The involvement of cell-to-cell signals in the development of a bacterial biofilm. Science 280, 295-298. doi: $10.1126 /$ science.280.5361.295

Desmarchelier, A., Mujahid, C., Racault, L., Perring, L., and Lancova, K. (2011). Analysis of patulin in pear-and apple-based foodstuffs by liquid chromatography electrospray ionization tandem mass spectrometry. J. Agric. Food Chem. 59, 7659-7665. doi: 10.1021/jf201461r

Ding, X., Yin, B., Qian, L., Zeng, Z., Yang, Z., Li, H., et al. (2011). Screening for novel quorum-sensing inhibitors to interfere with the formation 
of Pseudomonas aeruginosa biofilm. J. Med. Microbiol. 60, 1827-1834. doi: 10.1099/jmm.0.024166-0

Favre-Bonté, S., Pache, J. C., Robert, J., Blanc, D., Pechère, J. C., and Delden, C. V. (2002). Detection of Pseudomonas aeruginosa cell-to-cell signals in lung tissue of cystic fibrosis patients. Microb. Pathog. 32, 143-147. doi: 10.1006/mpat.2001.0487

Figueroa, M., Jarmusch, A. K., Raja, H. A., El-Elimat, T., Kavanaugh, J. S., Horswill, A. R., et al. (2014). Polyhydroxyanthraquinones as quorum sensing inhibitors from the guttates of Penicillium restrictum and their analysis by desorption electrospray ionization mass spectrometry. J. Nat. Prod. 77, 1351-1358. doi: 10.1021/np5000704

Flemming, H. C., and Wingender, J. (2010). The biofilm matrix. Nat. Rev. Microbiol. 8, 623-633. doi: 10.1038/nrmicro2415

Fux, C. A., Costerton, J. W., Stewart, P. S., and Stoodley, P. (2005). Survival strategies of infectious biofilms. Trends Microbiol. 13, 34-40. doi: 10.1016/j.tim.2004.11.010

Galloway, W. R., Hodgkinson, J. T., Bowden, S. D., Welch, M., and Spring, D. R. (2011). Quorum sensing in Gram-negative bacteria: small-molecule modulation of AHL and AI-2 quorum sensing pathways. Chem. Rev. 111, 28-67. doi: $10.1021 / \mathrm{cr} 100109 t$

Gamir, J., Pastor, V., Cerezo, M., and Flors, V. (2012). Identification of indole3-carboxylic acid as mediator of priming against Plectosphaerella cucumerina. Plant Physiol. Biochem. 61, 169-179. doi: 10.1016/j.plaphy.2012.10.004

Geske, G. D., O’Neill, J. C., Miller, D. M., Wezeman, R. J., Mattmann, M. E., Lin, Q., et al. (2008). Comparative analyses of $\mathrm{N}$-acylated homoserine lactones reveal unique structural features that dictate their ability to activate or inhibit quorum sensing. Chembiochem 9, 389-400. doi: 10.1002/cbic.200700551

Gong, A. S., Bolster, C. H., Benavides, M., and Walker, S. L. (2009). Extraction and analysis of extracellular polymeric substances: comparison of methods and ectracellular polymeric substance levels in Salmonella pullorum SA 1685. Environ. Eng. Sci. 26, 1523-1531. doi: 10.1089/ees.2008.0398

Gutiérrez-Barranquero, J. A., Reen, F. J., McCarthy, R. R., and O'Gara, F. (2015). Deciphering the role of coumarin as a novel quorum sensing inhibitor suppressing virulence phenotypes in bacterial pathogens. Appl. Microbiol. Biotechnol. 99, 3303-3316. doi: 10.1007/s00253-015-6436-1

Hall-Stoodley, L., and Stoodley, P. (2005). Biofilm formation and dispersal and the transmission of human pathogens. Trends Microbiol. 13, 7-10. doi: 10.1016/j.tim.2004.11.004

Han, X., Qiu, M., Wang, B., Yin, W. B., Nie, X., Qin, Q., et al. (2016). Functional analysis of the nitrogen metabolite repression regulator gene $\mathrm{nmrA}$ in Aspergillus flavus. Front. Microbiol. 7:1794. doi: 10.3389/fmicb.2016.01794

Hazen, G. G., Hause, J. A., and Hubicki, J. A. (1965). An automated system for the quantitative determination of proteolytic enzymes using azocasein. Ann. N.Y. Acad. Sci. 130, 761-768. doi: 10.1111/j.1749-6632.1965. tb12620.x

Hunter, R. C., Klepac-Ceraj, V., Lorenzi, M. M., Grotzinger, H., Martin, T. R., and Newman, D. K. (2012). Phenazine content in the cystic fibrosis respiratory tract negatively correlates with lung function and microbial complexity. Am. J. Respir. Cell Mol. Biol. 47, 738-745. doi: 10.1165/rcmb.2012$0088 \mathrm{OC}$

Husain, F. M., Ahmad, I., Khan, M. S., Ahmad, E., Tahseen, Q., Shahnawaz, M., et al. (2015). Sub-MICs of Mentha piperita essential oil and menthol inhibits AHL mediated quorum sensing and biofilm of Gram-negative bacteria. Front. Microbiol. 6:420. doi: 10.3389/fmicb.2015.00420

Imperi, F., Leoni, L., and Visca, P. (2014). Antivirulence activity of azithromycin in Pseudomonas aeruginosa. Front. Microbiol. 5:178. doi: $10.3389 /$ fmicb. 2014.00178

Jones, B. V., Young, R., Mahenthiralingam, E., and Stickler, D. J. (2004). Ultrastructure of Proteus mirabilis swarmer cell rafts and role of swarming in catheter-associated urinary tract infection. Infect. Immun. 72, 3941-3950. doi: 10.1128/IAI.72.7.3941-3950.2004

Kandasamy, P., Manogaran, S., Dhakshinamoorthy, M., and Packiam, K. K. (2015). Evaluation of antioxidant and antibacterial activities of endophytic fungi isolated from Bauhinia racemosa Lam and Phyllanthus amarus Schum and Thonn. J. Chem. Pharm. Res. 7, 366-379.

Kaplan, J. B. (2010). Biofilm dispersal: mechanisms, clinical implications, and potential therapeutic uses. J. Dent. Res. 89, 205-218. doi: $10.1177 / 0022034509359403$
Karatan, E., and Watnick, P. (2009). Signals, regulatory networks, and materials that build and break bacterial biofilms. Microbiol. Mol. Biol. Rev. 73, 310-347. doi: 10.1128/MMBR.00041-08

Kim, H. S., Lee, S. H., Byun, Y., and Park, H. D. (2015). 6-Gingerol reduces Pseudomonas aeruginosa biofilm formation and virulence via quorum sensing inhibition. Sci. Rep. 5:8656. doi: 10.1038/srep08656

Kim, H. S., and Park, H. D. (2013). Ginger extract inhibits biofilm formation by Pseudomonas aeruginosa PA14. PLoS ONE 8:e76106. doi: 10.1371/journal.pone.0076106

Kawai, K., Kato, T., Mori, H., Kitamura, J., and Nozawa, Y. (1984). A comparative study on cytotoxicities and biochemical properties of anthraquinone mycotoxins emodin and skyrin from Penicillium islandicum sopp. Toxicol. Lett. 20, 155-160. doi: 10.1016/0378-4274(84)90141-3

Kong, D. X., Ren, W., Lü, W., and Zhang, H. Y. (2009). Do biologically relevant compounds have more chance to be drugs? J. Chem. Inf. Model. 49, 2376-2381. doi: $10.1021 / \mathrm{ci} 900229 \mathrm{c}$

LaSarre, B., and Federle, M. J. (2013). Exploiting quorum sensing to confuse bacterial pathogens. Microbiol. Mol. Biol. Rev. 77, 73-111. doi: 10.1128/MMBR.00046-12

Lindow, S. E., and Brandl, M. T. (2003). Microbiology of the phyllosphere. Appl. Environ. Microbiol. 69, 1875-1883. doi: 10.1128/AEM.69.4.1875-1883.2003

Liu, Y., Yang, C. H., and Li, J. (2007). Influence of extracellular polymeric substances on Pseudomonas aeruginosa transport and deposition profiles in porous media. Environ. Sci. Technol. 41, 198-205. doi: 10.1021/es061731n

Liu, Y. C., Chan, K. G., and Chang, C. Y. (2015). Modulation of host biology by Pseudomonas aeruginosa quorum sensing signal molecules: messengers or traitors. Front. Microbiol. 6:1226. doi: 10.3389/fmicb.2015.01226

Lu, C., Maurer, C. K., Kirsch, B., Steinbach, A., and Hartmann, R. W. (2013). Overcoming the unexpected functional inversion of a PqsR antagonist in Pseudomonas aeruginosa: an in vivo potent antivirulence agent targeting pqs quorum sensing. Angew. Chem. Int. Ed. Engl. 53, 1109-1112. doi: 10.1002 /anie. 201307547

Luo, J., Kong, J. L., Dong, B. Y., Huang, H., Wang, K., Wu, L., et al. (2016). Baicalein attenuates the quorum sensing-controlled virulence factors of Pseudomonas aeruginosa and relieves the inflammatory response in $P$. aeruginosa-infected macrophages by downregulating the MaPK and NFאB signal-transduction pathways. Drug Des. Dev. Ther. 10, 183-203. doi: 10.2147/DDDT.S 97221

Lv, D., Ma, A., Tang, X., Bai, Z., Qi, H., and Zhuang, G. (2013). Profile of the culturable microbiome capable of producing acyl-homoserine lactone in the tobacco phyllosphere. J. Environ. Sci. 25, 357-366. doi: 10.1016/S1001-0742(12)60027-8

Michalska, M., and Wolf, P. (2015). Pseudomonas Exotoxin A: optimized by evolution for effective killing. Front. Microbiol. 6:963. doi: $10.3389 /$ fmicb. 2015.00963

Morin, D., Grasland, B., Vallee-Rehel, K., Dufau, C., and Haras, D. (2003). Online high-performance liquid chromatography-mass spectrometric detection and quantification of $\mathrm{N}$-acylhomoserine lactones, quorum sensing signal molecules, in the presence of biological matrices. J. Chromatogr. A 1002, 79-92. doi: 10.1016/s0021-9673(03)00730-1

Morita, Y., Tomida, J., and Kawamura, Y. (2014). Responses of Pseudomonas aeruginosa to antimicrobials. Front. Microbiol. 4:422. doi: 10.3389/fmicb.2013.00422

Nadell, C. D., Xavier, J. B., Levin, S. A., and Foster, K. R. (2008). The evolution of quorum sensing in bacterial biofilms. PLoS Biol. 6:e14. doi: 10.1371/journal.pbio.0060014

Ohman, D., Cryz, S., and Iglewski, B. (1980). Isolation and characterization of Pseudomonas aeruginosa PAO mutant that produces altered elastase. J. Bacteriol. 142, 836-842.

O'Loughlin, C. T., Miller, L. C., Siryaporn, A., Drescher, K., Semmelhack, M. F., and Bassler, B. L. (2013). A quorum-sensing inhibitor blocks Pseudomonas aeruginosa virulence and biofilm formation. Proc. Natl. Acad. Sci. U.S.A. 110, 17981-17986. doi: 10.1073/pnas.1316981110

Osono, T. (2006). Role of phyllosphere fungi of forest trees in the development of decomposer fungal communities and decomposition processes of leaf litter. Can. J. Microbiol. 52, 701-716. doi: 10.1139/w06-023

Owlia, P., Rasooli, I., Saderi, H., and Aliahmadi, M. (2007). Retardation of biofilm formation with reduced productivity of alginate as a result of Pseudomonas 
aeruginosa exposure to Matricaria chamomilla essential oil. Pharmacogn. Mag. 3, 83-89.

Panda, P. S., Chaudhary, U., and Dube, S. K. (2016). Comparison of four different methods for detection of biofilm formation by uropathogens. Indian J. Pathol. Microbiol. 59, 177-179. doi: 10.4103/0377-4929.182013

Pearson, J. P., Feldman, M., Iglewski, B. H., and Prince, A. (2000). Pseudomonas aeruginosa cell-to-cell signaling is required for virulence in a model of acute pulmonary infection. Infect. Immun. 68, 4331-4334. doi: 10.1128/IAI.68.7.4331-4334.2000

Ping, F. (2009). Preliminary study on antimicrobial activity screening of 10 kind of wild vegetables. J. Anhui Agric. Sci. 24:009.

Pompilio, A., Crocetta, V., De Nicola, S., Verginelli, F., Fiscarelli, E., Di Bonaventura, G., et al. (2015). Cooperative pathogenicity in cystic fibrosis: Stenotrophomonas maltophilia modulates Pseudomonas aeruginosa virulence in mixed biofilm. Front. Microbiol. 6:951. doi: 10.3389/fmicb.2015. 00951

Qin, N., Tan, X., Jiao, Y., Liu, L., Zhao, W., Yang, S., et al. (2014). RNA-Seq-based transcriptome analysis of methicillin-resistant Staphylococcus aureus biofilm inhibition by ursolic acid and resveratrol. Sci. Rep. 4:5467. doi: 10.1038/srep05467

Rasmussen, R. R., Storm, I. M., Rasmussen, P. H., Smedsgaard, J., and Nielsen, K. F. (2010). Multi-mycotoxin analysis of maize silage by LC-MS/MS. Anal. Bioanal. Chem. 397, 765-776. doi: 10.1007/s00216-010-3545-7

Rasmussen, T. B., Skindersoe, M. E., Bjarnsholt, T., Phipps, R. K., Christensen, K. B., Jensen, P. O., et al. (2005). Identity and effects of quorum-sensing inhibitors produced by Penicillium species. Microbiology 151, 1325-1340. doi: $10.1099 /$ mic. $0.27715-0$

Rendueles, O., Kaplan, J. B., and Ghigo, J. M. (2013). Antibiofilm polysaccharides. Environ. Microbiol. 15, 334-346. doi: 10.1111/j.1462-2920.2012.02810.x

Ricucci, D., and Siqueira, J. F. (2010). Biofilms and apical periodontitis: study of prevalence and association with clinical and histopathologic findings. J. Endod. 36, 1277-1288. doi: 10.1016/j.joen.2010.04.007

Rutherford, S. T., and Bassler, B. L. (2012). Bacterial quorum sensing: its role in virulence and possibilities for its control. Cold Spring Harb. Perspect. Med. 2:a012427. doi: 10.1101/cshperspect.a012427

Sanchez-Vallet, A., Ramos, B., Bednarek, P., López, G., Piślewska-Bednarek, M., Schulze-Lefert, P., et al. (2010). Tryptophan-derived secondary metabolites in Arabidopsis thaliana confer non-host resistance to necrotrophic Plectosphaerella cucumerina fungi. Plant J. 63, 115-127. doi: 10.1111/j.1365-313x.2010.04224.x

Sheng, J. Y., Chen, T. T., Tan, X. J., Chen, T., and Jia, A. Q. (2015). The quorum-sensing inhibiting effects of stilbenoids and their potential structure-activity relationship. Bioorg. Med. Chem. Lett. 25, 5217-5220. doi: 10.1016/j.bmcl.2015.09.064

Singh, P. K., Schaefer, A. L., Parsek, M. R., Moninger, T. O., Welsh, M. J., and Greenberg, E. P. (2000). Quorum-sensing signals indicate that cystic fibrosis lungs are infected with bacterial biofilms. Nature 407, 762-764. doi: $10.1038 / 35037627$

Smith, R. (2003). P. aeruginosa quorum-sensing systems and virulence. Curr. Opin. Microbiol. 6, 56-60. doi: 10.1016/S1369-5274(03)00008-0

Song, R., Xu, F., Zhang, Z., Liu, Y., Dong, H., and Tian, Y. (2008). Structural elucidation of in vitro metabolites of emodin by liquid chromatographytandem mass spectrometry. Biomed. Chromatogr. 22, 1230-1236. doi: $10.1002 /$ bmc. 1050

Storz, M. P., Maurer, C. K., Zimmer, C., Wagner, N., Brengel, C., de Jong, J. C., et al. (2012). Validation of PqsD as an anti-biofilm target in Pseudomonas aeruginosa by development of small-molecule inhibitors. J. Am. Chem. Soc. 134, 16143-16146. doi: 10.1021/ja3072397

Uroz, S., Dessaux, Y., and Oger, P. (2009). Quorum sensing and quorum quenching: the yin and yang of bacterial communication. Chembiochem 10, 205-216. doi: 10.1002/cbic.200800521
Vadekeetil, A., Saini, H., Chhibber, S., and Harjai, K. (2016). Exploiting the antivirulence efficacy of an ajoene-ciprofloxacin combination against biofilm associated murine acute pyelonephritis. Biofouling 32, 371-382. doi: 10.1080/08927014.2015.1137289

Venturi, V. (2006). Regulation of quorum sensing in Pseudomonas. FEMS Microbiol. Rev. 30, 274-291. doi: 10.1111/j.1574-6976.2005.00012.x

Wang, L., Zou, S., Yin, S., Liu, H., Yu, W., and Gong, Q. (2011). Construction of an effective screening system for detection of Pseudomonas aeruginosa quorum sensing inhibitors and its application in bioautographic thin-layer chromatography. Biotechnol. Lett. 33, 1381-1387. doi: 10.1007/s10529-011-0563-2

Welsh, M. A., Eibergen, N. R., Moore, J. D., and Blackwell, H. E. (2015). Small molecule disruption of quorum sensing cross-regulation in Pseudomonas aeruginosa causes major and unexpected alterations to virulence phenotypes. J. Am. Chem. Soc. 137, 1510-1519. doi: 10.1021/ja5110798

Wu, D., Huang, W., Duan, Q., Li, F., and Cheng, H. (2014). Sodium houttuyfonate affects production of $\mathrm{N}$-acyl homoserine lactone and quorum sensingregulated genes expression in Pseudomonas aeruginosa. Front. Microbiol. 5:635. doi: 10.3389/fmicb.2014.00635

Wu, N., He, L., Cui, P., Wang, W., Yuan, Y., Liu, S., et al. (2015). Ranking of persister genes in the same Escherichia coli genetic background demonstrates varying importance of individual persister genes in tolerance to different antibiotics. Front. Microbiol. 6:1003. doi: 10.3389/fmicb.2015.01003

Wu, S., Liu, G., Jin, W., Xiu, P., and Sun, C. (2016). Antibiofilm and anti-infection of a marine bacterial exopolysaccharide against Pseudomonas aeruginosa. Front. Microbiol. 7:102. doi: 10.3389/fmicb.2016.00102

Xin, Z. H., Li-Tian, T. Z., Zhu, T., Wang, W. L., Du, L., Fang, Y. C., et al. (2007). Isocoumarin deritives from the sea squirtderived fungus Pencillium stoloniferum QY2-10 and the haltolerant fungus Penicillium notatum B-52. Arch. Pharm. Res. 30, 816-819. doi: 10.1007/BF02978830

Zhan, Y., Xu, Z., Guo, X., Li, R., Shen, J., Xu, X., et al. (2016). Protective effect of Orychophragmus violaceus seed against acute liver injury induced by Cortex Dictamni in mice. Chin. J. Pharmacol. Toxicol. 30, 101-106.

Zhang, S. P., Huang, R., Li, F. F., Wei, H. X., Fang, X. W., Xie, X. S., et al. (2016). Antiviral anthraquinones and azaphilones produced by an endophytic fungus Nigrospora sp. from Aconitum carmichaeli. Fitoterapia 112, 85-89. doi: 10.1016/j.fitote.2016.05.013

Zhang, T., Wang, N. F., Liu, H. Y., Zhang, Y. Q., and Yu, L. Y. (2016). Soil $\mathrm{pH}$ is a key determinant of soil fungal community composition in the Ny-Alesund region, Svalbard (high arctic). Front. Microbiol. 7:227. doi: $10.3389 /$ fmicb.2016.00227

Zhang, X., Li, J., Cheng, Z., Zhou, Z., and Ma, L. (2016). High-performance liquid chromatography-tandem mass spectrometry method for simultaneous detection of ochratoxin A and relative metabolites in Aspergillus species and dried vine fruits. Food Addit. Contam. Part A Chem. Anal. Control Expo. Risk Assess. 33, 1355-1366. doi: 10.1080/19440049.2016.1209691

Zulianello, L., Canard, C., Köhler, T., Caille, D., Lacroix, J.-S., and Meda, P. (2006). Rhamnolipids are virulence factors that promote early infiltration of primary human airway epithelia by Pseudomonas aeruginosa. Infect. Immun. 74, 3134-3147. doi: 10.1128/IAI.01772-05

Conflict of Interest Statement: The authors declare that the research was conducted in the absence of any commercial or financial relationships that could be construed as a potential conflict of interest.

Copyright (C) 2017 Zhou, Bi, Chen, Chen, Yang, Li, Fu and Jia. This is an open-access article distributed under the terms of the Creative Commons Attribution License (CC $B Y)$. The use, distribution or reproduction in other forums is permitted, provided the original author(s) or licensor are credited and that the original publication in this journal is cited, in accordance with accepted academic practice. No use, distribution or reproduction is permitted which does not comply with these terms. 